\title{
NUMERICAL ANALYSIS OF THE LOAD-BEARING CAPACITY OF BRICK MASONRY WALLS STRENGTHENED WITH TEXTILE REINFORCED MORTAR AND SUBJECTED TO ECCENTRIC COMPRESSIVE LOADING
}

\author{
Ernest Bernat ${ }^{\mathrm{a}^{*}}$, Lluis Gil ${ }^{\mathrm{a}}$ and Pere Roca ${ }^{\mathrm{b}}$ \\ ${ }^{a}$ Department of Strength of Materials and Engineering Structures \\ Technical University of Catalonia. Colom 11. 08222 Terrassa, Spain \\ ${ }^{\mathrm{b}}$ Department of Construction Engineering \\ Technical University of Catalonia. Jordi Girona 1-3. 08034 Barcelona, Spain
}

\begin{abstract}
A numerical model has been implemented to simulate brick masonry walls strengthened with Textile Reinforced Mortar (TRM) and subjected to second order bending effects in order to cover the limited research in this area. Simulations have been compared with experimental cases and applied to enhance the knowledge about the influence of different strengthening variables. The model is accurate at predicting the load-bearing capacity of the walls, which might be increased by strengthening both sides. Moreover, the TRM is more effective for the most slender cases and the numerical results suggest future improvements to reproduce the wall's stiffness.
\end{abstract}

\section{KEYWORDS}

Masonry; Walls; Finite Element Analysis; Textile Reinforced Mortar; Second Order Bending

* Corresponding author:

Tel.: +34 937398728; fax: 937398994

e-mail address: ernest.bernat@upc.edu 


\section{INTRODUCTION}

The structural response of load-bearing brick masonry walls is characterised by the almost negligible tensile strength of this material. This property defines the most common structural failure modes which affect these elements. Among them, the buckling-bending mixed failure is significant because of the risky and sudden development of this collapse, which might be favoured by eccentric compressive loads [1]. Using composite materials to provide tensile strength and avoid this failure mode has been proved to be effective in a previous research [2].

Fibre Reinforced Polymer (FRP) and Textile Reinforced Mortar (TRM) are common strengthening solutions for concrete and masonry structures. TRM (also called Fabric Reinforced Cementitious Matrix, FRCM) is a composite material consisting of a textile grid embedded into an inorganic matrix. The textile grid is commonly made of high strength materials like glass, basalt or carbon fibres, whereas the inorganic matrix is usually a cement or lime mortar. The physical properties of these inorganic matrixes allow a better physical compatibility with masonry substrates than other adhesives (e.g. epoxy resins). In fact, different inorganic mortars are available so it is possible to select the one which provides better compatibility with the particular masonry to be strengthened. For example, lime-based matrixes are normally suitable for historic masonry and cement-based ones are more proper for contemporary masonry. Because of this physical compatibility, several authors [3-5] present the TRM as an appropriate strengthening solution for masonry structures. The advantages of TRM in front of other possible strengthening solutions based on organic matrixes (e.g. Fibre Reinforced Polymer, FRP), have been reported in by Papanicolaou et al. $[6,7]$. The main differences between these two strengthening systems arise from the organic/inorganic nature of the corresponding matrix.

Load-bearing brick masonry walls were extensively used in residential buildings up to the first half of the $20^{\text {th }}$ century worldwide. Although, these are the most common structural masonry elements among the existing constructions, most of the recent experimental researches about using TRM to strengthen masonry structures have focused on arches and curved surfaces $[5,8]$. This fact might be related with the remarkable shape adaptability of the TRM system, the possibility of removing it in an easier way than other strengthening options, like the FRP, and its mechanical compatibility with masonry. In particular, the relatively low modulus of elasticity of the TRM (if compared with other strengthening systems, like the FRP) makes it possible to strengthen ancient structures without introducing extremely rigid elements, which might cause significant modifications of the structural response and introduce stress concentrators which might damage the original structure. Thus, the TRM seems a suitable solution for strengthening historical constructions where arches are common structural elements.

The bibliographic research revealed that there is little available experimental information about the application of TRM on masonry walls. The corresponding tests were focused on analysing the structural response against in-plane loads [3,4] or out-of-plane cyclic loads [9]. However, in non-seismic areas the horizontal in-plane loading conditions might be not critical. Instead, the compressive loads transmitted by roofs or slabs can be crucial if they are eccentrically applied on the wall's thickness. These loads might induce second order bending 
effects causing a flexural-buckling mixed failure [1]. In this line, only a few experimental researches have studied the second order bending effects on TRM strengthened brick masonry walls [10].

Despite the significance of this structural problem, it has to be highlighted that performing experimental tests to analyse the load-bearing capacity of full scale masonry walls strengthened with TRM and subjected to eccentric compressive loads requires a long-term and expensive research activity, and has been explored only by a few researches $[2,10]$. On the other hand, numerical modelling techniques provide an interesting and inexpensive tool for designing and assessing structures. However, no numerical model for the analysis of brick masonry walls strengthened with TRM and subjected to eccentric compressive loads, which might cause second order bending effects, is known by the authors.

The first researches dealing with the numerical simulation of the structural response of the TRM as a sole material have been recently published $[11,12]$. Other researchers have studied how to model the TRM-masonry interaction using masonry prisms as reference samples [13]. However, there are not known publications about modelling full scale TRM strengthened brick masonry structures. Conversely, the numerical analysis of reinforced concrete elements strengthened with TRM has received significant attention. In this line, some authors have dealt with numerical modelling TRM-strengthened reinforced concrete beams subjected to flexural loading conditions $[14,15]$, other have been focused on the shear strengthening [16] or on the numerical analysis of particular construction elements made of reinforced concrete like slabs [17] or beam-columns joints [18]. To some extent, the modelling of TRM reinforced concrete can be considered as a reference case and may provide some insight at modelling TRM reinforced masonry structures.

The simulations of FRP-strengthened masonry walls are reference cases for the analysed structural problem. These have been addressed from different points of view: considering the in-plane response [19], considering the out-of-plane behaviour [20], focusing on arches [21] or vaults [22], or the simulation of particular applications of the FRP on masonry walls as a continuous grid [23].

Thus, no specific research about the numerical simulation of TRM-strengthened brick masonry walls subjected to eccentric compressive loads has been found. Taking into account that assessing the load-bearing capacity of these structures is an essential part of the rehabilitation or strengthening interventions, which are aimed to enhance the life-cycle of the buildings, the current work presents the implementation of a numerical model aimed to cover this knowledge gap. The proposed simulations have been carried out using a commonly available commercial Finite Element Analysis (FEA) package to spread the possibility of being used by practitioners. In addition, it has been intended to keep the model as simple as possible while assuring the required accuracy. This simplicity is oriented to allow a wider utilization among researchers and practitioners and, specifically, to permit its implementation in other FEA packages. This accuracy level is estimated to correspond with a relative error of the predicted load-bearing capacity below $25 \%$. This threshold value might be set by comparison with the scattering of the experimental results on masonry walls, which is around $30 \%$ (see [1]). Thus, 
limiting the relative error at a slightly lower value than the typical scattering seems a reasonable approach.

\section{SCOPE AND METHODS}

The work presented herein is the continuation of two previous researches: one about testing and modelling unreinforced brick masonry walls [1] and another based on the experimental and analytical investigation about the structural response of TRM-strengthened brick masonry walls [2]. It has to be highlighted that the scope of the current work is limited to brick masonry walls subjected to eccentric compressive loads which are strengthened with TRM to avoid the mixed buckling-bending failure. The numerical model described later on in section 3 is aimed to complement the previous calculation models for unreinforced masonry walls [1] with the inclusion of the TRM strengthening system. Hence, the main objective of this model is to predict the load-bearing capacity of these strengthened walls.

The applied methodology consisted of implementing a numerical model for predicting the load-bearing capacity of TRM-strengthened walls subjected to eccentric compressive loads, validating this numerical tool by comparison with experimental results, comparing the accuracy of this model with the accuracy of an specific analytical method and finally, extending the experimental results including the analysis of different theoretical cases to enhance the understanding about the influence of different strengthening variables of the TRM.

\subsection{Experimental cases for validation}

The implemented numerical model has been applied to calculate the load-bearing capacity of 9 TRM-strengthened walls which were previously tested up to failure. This procedure has allowed assessing the accuracy of the proposed tool. The comparison walls were part of a larger experimental campaign and their mechanical details are fully described in [2]. The main geometric characteristics of these structures and the corresponding typology of strengthening are summarised in Table 1. Table 2 , which includes data previously presented in communications [1,2], provides all required information to follow the current work. The mechanical properties of the bricks, bricklayering mortar, and strengthening mortars is included in Table 2. The compressive strength of the used masonry was $10.8 \mathrm{MPa}$, its flexural strength was $0.36 \mathrm{MPa}$ and the Young's modulus was $780 \mathrm{MPa}$, which is 72.22 times the compressive strength (see [1]). Table 3 summarises the properties of the fibre grids provided by the manufacturers.

The 9 TRM-strengthened walls were tested in a pinned-pinned configuration with the aims of clearly identifying the boundary conditions and easing the comparison with the numerical model. In addition, the strengthening system was always placed in the side of the wall subjected to tensile stresses because it was assumed that the TRM would be more efficient when installed on this side.

The name of the experimentally tested walls is summarised in the first column of Table 1 . The thickness of the walls, without considering the strengthening system, was $132 \mathrm{~mm}$ and their width was $900 \mathrm{~mm}$. The second column shows the experimentally obtained effective height, $H_{e f}$, of each wall. $H_{e f}$ is the vertical distance between the axes of rotation of the two hinges. $d$ is 
the measurement of the horizontal distance between the axes of rotation of the hinges. $d$ provides an indirect way to measure the geometric imperfections of the tested walls. The last five columns in Table 1 are dedicated to characterise the TRM and they include the type of mortar ( $M$ for the Portland based mortar, $R$ for the lime-based mortar and $X$ for the pozzolanic mortar as presented in [2]), the type of fibre grid ( $G$ for glass and $C$ for carbon), the presence of connectors, the number of fibre grids installed into the mortar layer and the real thickness of the TRM layer.

Two failure modes were experimentally observed: the tensile failure of the TRM associated with a mechanism formation process (W\#21 and W\#23) and the shear/compressive failure near the endings of the wall. Moreover, the real geometric imperfections were measured and introduced into the numerical model through the geometry definition. The measurement process consisted on determining the distance between a vertically aligned profile and the wall when it was placed in the testing position. A laser sensor was used for this purpose and measurements were carried out every two masonry rows at the two largest edges of one of the two biggest faces of the walls. These measurements allowed determining the shape of the wall (imperfections respect the plane) and the parameter $d$ (imperfections respect the verticality of the wall).

\subsection{Analytical approach for comparison}

The results of the implemented numerical model at calculating the load-bearing capacity of the experimental cases are also compared with the results obtained by applying the analytical approach recently presented in [2]. This analytical model is based on the assumption that the stresses are linearly distributed along the wall's thickness, which is a non-conventional hypothesis. However, it is supported by the good accuracy which was obtained.

This analytical approach is based on the force and flexural equilibrium equations and the strain compatibility expressions that allow obtaining the axial $(N)$ versus bending moment $(M)$ failure criteria assuming two possible failure modes: the tensile failure of the TRM and the compressive failure of the masonry.

\subsection{Theoretical cases}

After comparing the proposed numerical model with the experimental cases and assessing its accuracy in comparison with an analytical method, the implemented tool was used to predict the load-bearing capacity of a series of 14 theoretical walls. This second series of simulations was set to analyse different variables of the TRM strengthening system: the influence of placing two or more fibre grids embedded into the strengthening layer, the effect of strengthening both sides instead of strengthening only one side and the influence of the slenderness of the wall (by considering two heights, which correspond to the experimental $\mathrm{M}$ and $\mathrm{H}$ series in [24][24][24][1]) on the effectiveness of the strengthening system. In addition, these theoretical cases were used to analyse the influence of some simplifications assumed when modelling the TRM strengthened walls, as presented in section 3.2.

The geometric characteristics and the configuration of the strengthening system used in each theoretical wall are summarised in Table 4. It has to be highlighted that the thickness of the TRM, $t_{T R M}$, is kept constant $(10 \mathrm{~mm})$ when embedding one or two fibre grids according with the experimental evidences presented in [2]. However, this thickness is doubled when placing four 
fibre grids. In turn, one fibre grid is considered for each TRM layer in the cases of the walls which are strengthened at both sides. The name of the walls presented in Table 4 should be understood as follows: the first letter is associated with the height of the wall (medium, $M$ or high, $H$ ), the second symbol is a $O$ if it is an unreinforced wall and it is an $S$ if the wall is strengthened with TRM, the third symbol (optional) corresponds to the number of sides strengthened with TRM, the fourth (optional) is the number of fibre grids installed in each strengthened side and the last symbol is an $S$ if the inclined contact (see section 3.1) at the endings of the wall is considered. This position is kept empty if this contact is not considered.

Finally, it has to be noted that no connectors were considered for the theoretical cases because the experimental evidence pointed out that these elements were not efficiently contributing at increasing the load-bearing capacity of TRM strengthened brick masonry walls subjected to eccentric compressive loads.

\section{NUMERICAL MODEL}

The implemented model assumes the hypothesis of plane strain applied to a bi-dimensional (2D) description of a typical transverse section of the wall. Such a model is a 2D simplification of the three-dimensional (3D) real case. Using a 2D simplification reduces the computational cost of the analysis and simplifies the definition of the materials and contacts. The plane strain hypothesis requires a uniform definition of the problem along the direction which is perpendicular to the simulated section. For the particular case of compressed masonry walls, this means that the load is uniformly applied along the wall's width. In addition, the strains which are oriented perpendicular to the analysis plane are supposed to be negligible in both masonry and TRM. This hypothesis is closer than the plane stress option for most of the real walls, which are wider than the tested ones and are usually laterally restrained. In fact, the plane stress approach might certainly be more representative of the tested comparison walls than the plane strain one, but the aim of the proposed model is to cover the most representative situation. Because of this, the plain strain simplification has been adopted. This means that the model presented herein might be not suitable for calculating TRMstrengthened masonry piers.

In addition, simplified micromodelling has been used because this approach does not require so much information of the material properties as detailed micromodelling but performs better than macromodels. The detailed micromodelling option would represent bricks, mortars, fibre grids and their interfaces separately. The macromodelling technique would require a complex homogenisation process to obtain a unique equivalent material. In fact, the proposed method is something intermediate. It models each brick together with the surrounding mortar as a homogenised material, called masonry, and uses the corresponding properties. Thus, no homogenisation process is required because the experimentally obtained properties of the equivalent material (masonry) are directly used. Similarly, the TRM is though as a homogeneous material and the equivalent properties of this composite are used. These properties gather the effect of the mortar, the fibre grid and the interfaces between them and with the masonry. The only particularity of the proposed approach is about the definition of the tensile strength of the TRM, which is explained with detail in section 3.2.2. Contacts are defined between the objects that represent each masonry row or each fictitious TRM row (see 
sections 3.1 and 3.2). This approach saves over half of the contacts and the material definitions - in comparison with detailed micromodel - and thus, eases the convergence of the numerical simulation.

In addition, the numerical model has been implemented to calculate the structure by considering large displacements to accurately represent the buckling phenomena originated by the second order bending effects.

This numerical tool uses ANSYS ${ }^{\circledR}$ v.12.1 and the materials, contacts and geometric definitions have been set as general as possible to assure that the model can be reproduced in general purpose Finite Element Analysis (FEA) packages.

\subsection{Geometry}

The geometric model is defined as a series of piled rectangular parts corresponding to the different masonry rows existing in the analysed wall. In addition, rectangular bodies are placed next to the ones representing the masonry wall to describe the TRM layer (see Figure 1 and Figure 2). Contacts between the different parts representing the TRM layer are defined to allow modelling the tensile failure of the TRM observed in two experimental cases (see [2]). The interface between the brick masonry and the TRM is also described by means of contact elements.

Two extra bodies, which are two triangles, one at each end of the wall (see Figure 1), are defined to easily represent the hinges of the pinned-pinned configuration considered for all experimental and theoretical cases. These triangles allow placing the load application point accurately and setting the rotation axes.

In addition, fictitious contacts are placed in an inclined line crossing and dividing the masonry bodies near the extremes of the walls (see Figure 2). The purpose of these inclined contacts is modelling the compressive/out-of-plane shear collapse mode, which was experimentally observed in most of the TRM strengthened walls (see [2]). This failure mode was characterised by the opening of one diagonal crack, which always started from one extreme of the strengthened side of the wall and grew to the compressed side of the structure. The chosen orientation for these dividing lines was set to be constant and this corresponded to the average inclination of the cracking lines which were observed in the experimental collapses. Thus, only the most representative situation is taken into account for the geometric input of the numerical model. For comparison purposes, wall W\#21, which collapsed due to the tensile failure of the TRM, was modelled with and without these inclined fictitious contacts to assure that these do not influence on the results when the failure mode is not characterised by the compressive/shear collapse.

The experimental cases have been modelled considering their real geometry in a detailed way. The thickness of the TRM has been considered constant along the wall's height and equal to real TRM thickness at mid-height. In addition, the experimentally measured alignment of the hinges ( $d$ in Table 1 ) and the real shape of the wall are used to create the model. The real shape of the wall, taking into account its out-of-plane initial imperfections was determined by measuring it at each two brick rows. Thus, the definition of the geometry of the model has 
been carried out so as to capture the irregularities that might affect the development of second order bending effects.

An ideal geometry definition is considered for modelling the 14 theoretical cases $(132 \mathrm{~mm}$ thickness, $1 \mathrm{~m}$ width and two possible heights, $\mathrm{M}$ or $\mathrm{H}$ ). This decision allows comparing the considered strengthening variables without the interfering influence of the geometric imperfections. Thus, these walls are perfectly vertical, the hinges are horizontally aligned and the eccentricity of the load is always the same $(20 \mathrm{~mm})$. Two TRM thickness are considered for simulating these walls, equal to $10 \mathrm{~mm}$ if one or two fibre grids are embedded into the TRM layer and $20 \mathrm{~mm}$ for the cases with 4 fibre grids installed. The geometric variables are summarised in Table 4.

\subsection{Materials and contacts}

Strictly, the mechanical response of the brick masonry is orthotropic because of the pattern of the joints (see the work by Milani et al. [25]). In addition, masonry shows different failure modes determined by the units, the mortar or the interfaces between them, which are the components of this composite material. The failures that are linked to the interfaces refer to the joint opening or the join sliding mechanisms. In addition, there are several models which accurately represent the response of the masonry. Although these approaches could have been used in the implemented numerical approach (e.g. using a smeared crack approach from the research by Milani et al. [26]), they have been discarded because of their complex application and their requirement of advanced simulation tools, which would be against the first aim of the implemented model: keeping it as simple as possible.

Similarly, TRM, which is also a composite material, shows a complex structural response $[11,12,27]$. The compressive behaviour of the TRM is governed by the mortar matrix, whereas the tensile response is influenced by a) the mortar matrix (at low loads, before cracking and mobilising the fibre mesh), b) the fibre grid and c) the adherence between the mortar matrix and the fibre grid (at larger loads, after cracking). Typical stress-strain relationships of the TRM in tension are presented in the code ACl 549.4R-13 [28] (Fig. 5.3.2b of this standard) or by Bertolesi et al. [27] among others. Figure 3 is a sketch of the characteristic experimental response of the TRM under tensile forces. This realistic complex constitutive model is not used in the simulation. Instead, the adopted model is characterized by its simplicity. This assumption is required for an efficient calculation of the load bearing capacity of the TRM strengthened walls.

Thus, masonry and TRM are modelled as homogeneous materials, whose compressive response is defined with an isotropic linear elastic with perfect plasticity constitutive model. The typical compressive stress-strain diagram for masonry and TRM is shown in Figure 4, left. The compressive strength and the Young's modulus are the only required parameters to characterise these responses. On the other hand, the tensional behaviour of these materials is controlled by contact elements, which have neither thickness nor elastic properties. The sketch presented at the right side of Figure 4 show the used tensile constitutive law for the masonry and TRM. This is bilinear and it is defined by the tensile strength and the corresponding fracture energy, as detailed later on in this section. 
The current steel definition included in the FEA software is used to model the material of the parts corresponding with the hinges (end triangles in Figure 1).

Regarding the particular properties of the masonry, the following values are considered: the used density of the brickwork is $1732 \mathrm{~kg} / \mathrm{m}^{3}$, the Young's modulus of the masonry $(E)$ is $780 \mathrm{MPa}$, the compressive strength of the masonry $\left(f_{c}\right)$ is $10.8 \mathrm{MPa}(E / f c=72.22)$ and the corresponding Poisson's coefficient is set to 0.35 . The three first values were experimentally obtained and the Poisson's coefficient is based on the values found in the bibliography. For instance, Bosiljkov et al. [29] proposed values of Poisson's ratio up to 0.4 when using mortar with low content of cement. Moreover, Bosiljkov et al. [29] proposed a relationship between the modulus of elasticity and the Poisson's ratio. It was noticed that the highest Poisson's values corresponded with the lowest values of Young's modulus. For this reason, a relatively high value of the Poisson's coefficient $(u=0.35)$ is used in the current research if compared with the one proposed in Eurocode 6, which is 0.25 . In this line, the use of $u=0.35$ is completely supported by the experimental evidences in [29]. Nevertheless, a simple sensibility analysis was done to study the influence of this parameter and to assure that it was not crucial for the calculation of the load-bearing capacity. The results showed that the influence of the Poisson's coefficient on the resistance of the TRM-strengthened walls is limited. This fact was noticed by using two different and extreme values of Poisson's coefficient ( 0.10 and 0.45$)$ to model the theoretical case HO. The compared results pointed out that an increase of $350 \%$ of the Poisson's ratio was associated with a far littler increase of $23 \%$ of the ultimate load. Thus, slightly lower values of the load-bearing capacity (approximately $5 \%$ lower, if assuming a linear influence of the Poisson's ratio on this result) might have been obtained if considering a typical Poisson's coefficient of 0.25 instead of a more realistic and adjusted to the studied masonry one $(u=0.35)$. Hence, the value of the load-bearing capacity depends on the Poisson's coefficient but this dependence is less significant than the influence of other parameters such as load eccentricity, slenderness of the wall or Young's modulus of the masonry.

Taking into account the scattering of the experimentally determined properties of the masonry (specially the Young's modulus and the compressive strength), it was decided to perform a simplified sensibility analysis. This consisted in modelling three times every experimentally tested TRM-strengthened wall. The first time, using the average and most representative values for the compressive strength and the Young's modulus. A pair of low values for these parameters ( $E=400 \mathrm{MPa}, f_{c}=7 \mathrm{MPa}$ ) was considered in the second repetition, whereas the third time a couple of high values for these variables ( $\left.E=1100 \mathrm{MPa}, f_{c}=15 \mathrm{MPa}\right)$ was used. It has to be noticed that the low and high values are within the experimental range obtained for these variables [2].

On the other hand, the compressive behaviour of the TRM is associated with the properties of the strengthening mortar (Young's modulus and compressive strength). The present approach considers that the fibre grids do not influence on the compressive response of the TRM. Knowing that the influence of the Poisson's coefficient of the masonry on the load-bearing capacity is limited, in the case of the TRM this parameter was set to 0.35 , like for masonry. The compressive strength $\left(f_{c m}\right)$ and Young's modulus $\left(E_{m}\right)$ used for modelling each strengthening mortar are summarised in Table 2 . The values of the first two variables were experimentally obtained and $E_{m}$ was provided by the mortar's manufacturer. 
The tensile responses of masonry and TRM are modelled using contacts. At the first calculation step, these contacts are "bonded". It means that the corresponding nodes of the adjacent parts are set to move equally and together. The stress increase in the contact, which is associated with the step by step loading process described in section 3.4, might cause the opening (debonding) of the contacts or their relative sliding accordingly with the bilinear constitutive law shown in Figure 4. These tensile and/or shear responses of the contact elements are characterised by a cohesive zone model (CZM) that was originally proposed by Alfano et al. [30]. The CZM sets an elastic behaviour up to the brittle failure of the contact (see Figure 4, right). When the tensile or tangential strength is reached, the contact opens or slides while the corresponding stress decreases linearly with a slope that is defined by the corresponding fracture energy.

Modelling the contacts with the CZM allows using the relatively complex contact technology but requiring just of a few parameters: the tensile or shear strength and the corresponding fracture energy. Thus, it is believed that using the CZM is the simplest and most general way to represent the tensile response of the composite materials of the considered problem. In addition, using contacts is essential for the studied problem, which considers the second order bending effects.

The tensile strength $\left(f_{x t}\right)$ and the critical fracture energy of the first fracture mode $\left(G_{f}^{\prime}\right)$ are required by the CZM to model the debonding/opening phenomenon. The maximum shear stress $\left(\tau_{\max }\right)$ and the critical fracture energy of the second fracture mode $\left(G_{f}^{\prime \prime}\right)$ are required to model the sliding failure case. Failure modes involving debonding and sliding are modelled by a mixed failure criterion characterised by the power law energy criterion presented in the following equation (Eq. 1), where $G^{\prime}$ and $G^{\prime \prime}$ are, respectively, the normal and tangential energy of fracture for the case of combined failure.

$$
\left(\frac{G^{I}}{G_{f}^{I}}\right)+\left(\frac{G^{I I}}{G_{f}^{I I}}\right)=1
$$

The definition of every contact between two parts requires setting a pair of objects: a contact object and a contact target. Then, the characterisation of the state of the contact (penetrating, in contact, opening or sliding) is characterised by the relative position of one of this objects respect to the other.

Depending on the location of the contacts (see Figure 2), these might be classified into real contacts and fictitious contacts. The first ones correspond with the joints of the masonry and the interface between the TRM and the masonry. In contrast, the second ones are set in order to allow the development of the experimentally observed failure modes. Taking into account the real failure modes by defining fictitious contacts is the chosen approach to avoid using complex material definitions. All contacts are deeply described in the next subsections and summarised in Table 5.

\subsubsection{Real contacts}

There are real discontinuity surfaces between masonry rows and between TRM and masonry. These interfaces should be modelled with contacts. The experimental observation proves that the opening between masonry rows is likely to occur together with the tensile failure of the 
TRM. In contrast, no debonding process was observed between masonry and TRM during the tests, which consisted on applying eccentric compressive loads (see [2]). In addition, the sliding phenomenon was not experimentally noticed for these contacts and therefore, enabling the sliding capabilities of these contact elements is not considered to be necessary. Thus, the contacts between masonry and TRM are defined as "bonded". This definition forces the contact nodes of TRM and masonry to be always coincident, so moving equally. The same behaviour is defined for the contacts between the first and the last masonry rows with the corresponding triangular parts which represent the hinges.

The contacts between parts which represent masonry rows are initially defined as "bonded" but the possibility of debonding is considered through the definition of a CZM. This tensile response is bilinear and follows the constitutive law previously presented (see Figure 4, right). The sliding failure is not considered for these contacts because it was not experimentally observed. The values which have been used to define the debonding process $\left(f_{x t}\right.$ and $\left.G_{f}^{\prime}\right)$ are summarised in Table 5 . The flexural tensile strength, $f_{x t}$, which was experimentally determined through bond-wrench tests, is used instead of the direct tensile strength. It is because the flexural tensile strength is considered to be more representative of the response of the masonry under the second order bending phenomena. In fact, the contacts between masonry rows can be bended or compressed but not subjected to a tensile axial effort under the considered loading configuration. Thus, using the flexural strength of the masonry to calculate the bending response of walls is generally accepted. The proposed formulation to design outof plane loaded walls included in Eurocode 6 [31] is a reference example of this common assumption. Thus, taking into account that the studied walls are eccentrically compressed and their bending response due to second order effects is distinctive, the flexural tensile strength is chosen as the most suitable variable to characterise the behaviour of the contacts between masonry rows. Finally, the obtained results, in terms of load-bearing capacity, point out that the possible overestimation of the tensile strength of the contacts and the corresponding effect on the fracture energy, might not be a big deal because the numerical predictions tend to underestimate the capacity of the walls as presented in section 4 .

The fracture energy, $G_{f}^{\prime}$, is estimated using equation (Eq. 2). This expression has been adjusted using the experimental results presented in [32] and was previously used in [1].

$$
(N / m) G_{f}^{I}=36.65 \cdot f_{x t}(M P a)
$$

\subsubsection{Fictitious contacts}

Another two types of contacts, which do not correspond with real joints, are considered in the proposed model. These contacts set fictitious joints with the aim of representing the real failure modes without adding complexity to the material constitutive equations. Table 5 summarises the values of the properties used to define these fictitious contacts.

The first typology of fictitious contact is used between pairs of TRM parts. These contacts are defined to allow the opening but not the sliding between TRM parts. Thus, they make the TRM tensile failure (experimentally observed in walls $\mathrm{W} \# 21$ and $W \# 23$ ) possible. This tensile response follows a bilinear constitutive law presented in Figure 4 (right), and it is characterised by the tensile strength and the corresponding fracture energy. The first parameter, $f_{x t}$ is 
calculated as the maximum between: (a) the flexural tensile strength of the strengthening mortar and (b) the direct tensile strength of the fibre grid uniformly distributed on the area of the TRM section. In the case (a) the tensile force associated with the flexural tensile stresses on the mortar of the TRM is greater than the direct tensile resistance of the fibre grid embedded, which actually works in direct tension. Thus, in the case (a) the fibre grid cannot bear the tensile force released by the mortar when it cracks by bending, so the mortar completely controls the failure of the TRM. Similarly to the case of the contacts between masonry rows, the flexural tensile strength of the strengthening mortar is considered instead of the direct tensile strength. This assumption is based on the same hypotheses than for the masonry: the mortar of the TRM might be compressed or bended but never subjected to a direct tensile effort under the considered loading configuration, which tends to develop distinctive second order effects. Thus, the flexural tensile response of the mortar of the TRM is more representative than a direct tensile strength for the studied cases. In addition, these fictitious contacts might be understood as the natural extension of the real contacts between masonry rows into the TRM area, so using the same type of parameters is coherent. Finally, the tendency of the model to underestimate the load-bearing capacity of the studied walls (see section 4) subtracts importance to a possible overestimation of the tensile strength (and the corresponding fracture energy) of these fictitious contacts. On the other hand, the case (b) assumes that the force associated with tensile strength of the fibre grid (the mesh embedded into the TRM mostly works in direct tension) is greater than the resistance developed by the mortar in bending configuration. Thus, in the case (b) the fibre grid can bear larger load in direct tension than the mortar matrix up to its bending cracking time. It has to be noticed that (b) is the most likely case for practical strengthening applications. For these contacts the corresponding fracture energy was calculated using the expression presented in (Eq. 2) too.

The second type of fictitious contact is used in the two inclined lines that divide the five masonry rows near each end of a single wall. These contacts make it possible to simulate the compression/shear failure observed in most of the experimental tests on TRM strengthened walls. These enable the debonding and the sliding phenomena. Both tensile and shear responses are characterised by bilinear constitutive laws defined by the tensile or tangential strength and the corresponding fracture energy (first and second modes respectively). The tensile strength between two masonry parts of the same row, which are separated by the inclined discontinuity, is taken to be equal to the direct tensile strength of the ceramic pieces. This assumption is based on the idea that the bricks are not bended but subjected to direct tensile stresses on the plane of the considered fictitious contact, which just represents the connection between two parts of the same brick at each row. In addition, this inclined contact is almost perpendicular to the most bended plane orientation (horizontal) for the loading configuration of the studied walls. Thus, the direct tensile strength is understood to be more representative than the flexural one. The corresponding fracture energy is also calculated using (Eq. 2).

The maximum shear strength $\left(\tau_{\max }\right)$ is analytically calculated from the experimental data as showed below (Eq. 3). The corresponding fracture energy is calculated using (Eq. 2) where the flexural strength is replaced by the shear strength. Using (Eq. 2) for calculating the second mode fracture energy, $G_{f}^{\prime \prime}$, is a simplified approach, which has been assumed because a 
generally accepted formulation to calculate this required parameter for inclined contacts on masonry structures has not been found.

$$
\tau_{\max }=\frac{T}{b \cdot m}
$$

The load components, which are normal $(N)$ and tangential $(T)$ to the failure plane, are calculated from the maximum applied force $(F)$ and the observed failure modes (inclination of the crack in walls $W \# 22$ and $W \# 24$ to $W \# 29$ ) as shown in Figure 5 . Then, the tangential component $(T)$ is supposed to be uniformly distributed on the area $(b \cdot m)$ of the observed discontinuity plane. This allows obtaining the maximum shear strength (Eq. 3), where $b$ is the width of the wall and $m$ the length of the failure plane. The values used in the simulations are the average values for $\tau_{\max }$ and the corresponding $G_{f}^{\prime \prime}$.

It has to be highlighted that the used CZM model considers both fracture processes (opening and sliding of the contact) together, so the shear response is sensible to the normal response and vice versa.

\subsubsection{Failure criterion}

Each type of contact uses the corresponding failure criterion, which is defined under the specifications of the CZM model. Thus, the masonry joints fail in flexural tension when the corresponding strength is reached although the model allows larger deformations but at a lower stress levels. Similarly, the TRM fails in tension when the corresponding tensile strength is reached. The inclined contacts on masonry fail with a combination of the tensile and shear stresses that causes the opening or sliding of the contact. Like for the previous cases, larger deformations are allowed but with lower stress levels after reaching the maximum combined strength. All these failure criteria are local and refer to every node in the contact. In fact, the contact between each pair of nodes technically fails when all the energy of fracture has been dissipated, so there is no restrain for the independent displacement of the initially coincident nodes. The global failure criterion, which is used to set the load-bearing capacity of every studied structure, is reached when the resultant deformation due to the opening or sliding of the joints is not compatible with the internal equilibrium of the walls.

\subsection{Mesh}

Figure 2 shows a characteristic mesh used for the modelling. For all cases masonry and TRM are meshed with 8-nodes uniform structured quadrilateral elements with quadratic integration of the displacements. The average size of the elements is $3 \mathrm{~mm}$ for TRM and $5 \mathrm{~mm}$ for masonry, except the masonry of the theoretical walls with a height of $2900 \mathrm{~mm}$ ( $\mathrm{H}$ series) which uses elements with an average size of $20 \mathrm{~mm}$ to reduce the computational cost. The parts representing the steel hinges (triangles) are meshed with an unstructured uniform mesh composed by 6 -nodes triangular elements and 8 -nodes quadrilateral elements with quadratic integration of the displacements and an average size of $5 \mathrm{~mm}$.

Two types of elements are required to define the contacts. The first one is assigned to the contact body and overlays the 2D solid element, adopting the same shape and defining a boundary, whereas the second one is assigned to the target body. This last typology of element is defined as a set of segment elements placed at the edge of the corresponding solid 
element. The contact occurs when the contact element surface penetrates into one segment of the target element. Both element types have three nodes and the assignation of contact or target elements to one side or other of the contact is automatically done.

With the aim of adjusting the mesh size presented before, a sensibility analysis was done. This was performed under the requirement of carrying out the calculation in a reasonable time. This means spending less than 45 minutes in an Intel(R) Core(TM)2 Duo CPU E8400 @3.00GHz with $3.00 \mathrm{~GB}$ of RAM memory working with Windows7 32 bits.

A couple of cases were analysed to select the suitable mesh size. Changing the mesh size of the masonry from $5 \mathrm{~mm}$ to $3.5 \mathrm{~mm}$ and the TRM mesh size from $3 \mathrm{~mm}$ to $2 \mathrm{~mm}$ causes a change of the calculated maximum load-bearing capacity from $344.1 \mathrm{kN}$ to $344.0 \mathrm{kN}$ for wall W\#29, and changing the size of the masonry elements from $20 \mathrm{~mm}$ to $10 \mathrm{~mm}$ caused a difference less than $1 \%$ of the load-bearing capacity of one of the most slender walls (HS11 theoretical wall). Hence, the influence of the size of the elements is little for the selected sizes.

\subsection{Boundary conditions and loading process}

The boundary conditions of the model are defined to represent the real boundary conditions of the experimental cases. These are maintained for the theoretical cases and consisted of fixing the displacement of the lower hinge by restraining the horizontal and vertical displacements of the lowest vertex of the triangular part which represents the lower hinge. Additionally, the horizontal displacement of the top vertex of the triangular part representing the upper hinge is fixed. These constrains allow the structure to rotate around the restrained nodes while impeding any possible lateral displacement at the wall's ends.

The load is indirectly applied as a vertical descending displacement of the top vertex of the triangular part which represents the upper hinge. This movement is applied at a constant rate (step by step calculation) and the force reaction at the application point is taken as the measurement of the applied load for comparing with the experimental values. This displacement-controlled simulated loading process makes it possible to calculate some steps after reaching the maximum load, clarifying the interpretation of the failure pattern.

The calculation is performed step by step. Each new displacement increase is applied on the deformed configuration of the wall due to the previous loading steps. The number of calculation steps has to be little enough to complete the simulation with a reasonable cost (time elapsed). In addition, the first displacement increase has to be larger than the gravity deformation to avoid developing false tensile stress. However, the number of increments has to be sufficiently refined as to accurately capture the wall's response (approximately a minimum of 50 steps up to the collapse). For all these reasons, the loading ratio was carefully adjusted for each wall.

\section{RESULTS}

In order to analyse the numerical results and to compare them with the experimental evidences, a set of dimensionless variables are defined. The first one is the dimensionless applied load op (Eq. 4), calculated as the ratio of the applied load, $N$, over $N_{u}$ (Eq. 5). 


$$
\begin{gathered}
\phi=\mathrm{N} / \mathrm{N}_{\mathrm{u}} \\
N_{u}=b \cdot t \cdot f_{c}
\end{gathered}
$$

where $N_{u}$ is the compressive strength of the cross section assuming a uniform stress distribution on the width, $b$, and thickness, $t$, of the wall with a stress value corresponding to the compressive strength of the masonry, $f_{c}$.

Other calculated dimensionless variables are the mid-height lateral deformation, $h$, over the wall's thickness, $t$; the vertical displacement of the top hinge, $v$, over the effective height, $H_{e f}$, and the ratio between the eccentricity, $e$ over the wall's thickness, $t$.

The results considered for a possible validation of the numerical model are presented in Figures 6 and 7. In Figure 6, the vertical lines correspond to the range of possible values for the calculated load-bearing capacity depending on the considered compressive strength and Young's modulus of the masonry (see section 3.2). Analysing the length of these vertical lines it is noticed that the influence of these variables is more significant for the walls which were tested with the lowest eccentricities of the load. In addition, the horizontal lines in Figure 6 represent the calculated load-bearing capacity when using the most representative values for the compressive strength of the masonry and its Young's modulus. The circular points represent the experimentally determined load-bearing capacity of every tested TRMstrengthened wall (labelled next to the circular point). A relative error of $19.5 \%$ is obtained when comparing the numerically predicted load-bearing capacities with the experimental evidences. The model tends to underestimate the load-bearing capacity of the walls, especially in those cases whose eccentricity of the load is higher. Finally, the numerical results plotted in Figure 6 seem to point out that the eccentricity of the compressive load influences on the loadbearing capacity (the walls with major eccentricity are predicted to support minor loads). However, this tendency is not clear for the experimental results.

Figure 7 shows the experimental and numerical lateral responses of the tested TRMstrengthened walls. The relation between the dimensionless variables representing the lateral displacement at mid height and the applied force is represented. Two main results are obtained from these graphs: 1 ) the comparison of the stiffness of the lateral responses shows that the experimental behaviour is stiffer than the numerically predicted one; and 2) the characteristic shape of the curves which are linear for the numerical model and a parabolic for the experimental data.

Analytical results [2] are compared with the experimental and numerical ones to complement the evidences. These are all summarised in Table 6. It has to be noticed that the proposed numerical model tends to underestimate the load-bearing capacity of the tested walls except for the cases strengthened with carbon fibre meshes. In contrast, the analytical approach overestimates the load-bearing capacity. In addition, the results of the analytical approach suggest that the failure pattern is always associated with the compressive collapse of the masonry whereas the numerical simulation takes into account different failure possibilities. Thus, the simulation represents the observed failure modes in a more accurate way. The accuracy of both methods (relative error) at predicting the load-bearing capacity is in the same order of magnitude, although the numerical model is applicable in a wider range of cases and 
affords the simulation of a larger variety of failure modes. Finally, the dispersion of the numerically calculated load-bearing capacity of comparable walls is greater than the particular scattering of the experimental tests in this case (comparing walls W\#21 and W\#22 between them and W\#23 with W\#24).

The numerical results for theoretical walls are represented in Figures 8 and 9. The influence of considering the inclined contacts in those cases which are expected to fail due to mechanism formation ( $\mathrm{HO}, \mathrm{HS11}, \mathrm{MO}$ and MS11) is presented in Figure 8. It is noticed that considering these fictitious contacts does not affect the structural response of these walls which are not expected to fail due to compressive/shear forces near the endings. This result is obtained by comparing the lateral and vertical response of the theoretical case $\mathrm{HO}$ with $\mathrm{HOS}, \mathrm{HS} 11$ with HS11S, M0 with MOS and MS11 with MS11S. In addition, Figure 8 reveals that, according with the numerical results, the effectiveness of applying a TRM strengthening system is focused on the lateral response of the walls and their load-bearing capacity. In contrast, the vertical stiffness seems to be unaltered by the application of a TRM system. Finally, it is observed (see Figure 8) that the developed lateral deformation at the collapse instant is greater for the $\mathrm{H}$ series walls than for the $\mathrm{M}$ series walls.

Figure 9 shows the influence of the number of fibre grids embedded into the TRM layer on the wall's response and the effect of considering the application of the strengthening system at one face or both faces. Theoretical walls of the $\mathrm{H}$ and $\mathrm{M}$ series are considered and the influence of the slenderness is also studied. Observing these graphs of the numerical results it is noticed that the vertical stiffness of the walls is increased when both faces are considered to be strengthened. In contrast, this vertical stiffness is maintained for the other studied variations. In addition, the model predicts a lateral stiffness increase associated with the application of the TRM at one side. However, there is almost no difference between placing one or two fibre grids embedded into the mortar layer of the TRM. A slightly greater lateral stiffness is developed when placing 4 fibre grids (doubling the thickness of the mortar layer in this case). Thus, the major change is observed when strengthening both faces of the walls, like for the vertical response. Moreover, the differences between using 1, 2 or 4 fibre grids are more significant for the $\mathrm{M}$ series than for the $\mathrm{H}$ series. Finally, it is observed that the lateral deformation of the wall MS21S at the maximum load is greater than the corresponding value for the wall HS21S.

The analysis of the numerical results included in Table 7, which consider the influence of different strengthening configurations, shows that the performance of the TRM strengthening system at increasing the load-bearing capacity is enhanced by making the TRM layer thicker (compare the relative increase between HS11S and HS12S with the increase showed in the case HS14S; and similarly for M series) or applying the strengthening system at both faces of the wall. This last variation corresponds to the most effective one. Finally, the numerical predictions point out that TRM is more effective at increasing the load bearing capacity of the most slender cases.

Figures 10 and 11 show the typical contour plots resulting from the numerical simulations. The pressure distribution along fictitious contacts between TRM elements is presented in Figure 10 (left) for the case HS11S, which fails due to mechanism formation according with the results of 
the proposed model. In this image (Figure 10 left), it might be observed that the tensile strength of the TRM is simultaneously reached at the two contacts which are placed near midheight. This fact corresponds with the experimental experience, which suggests that the tensile failure of the TRM usually happens at mid height.

Similarly, the tangential stress distribution along the fictitious inclined contacts can be observed in Figure 10 (right). This image corresponds to the theoretical wall MS12S, which fails due to masonry compressive/shear collapse near the ends of the wall, according with the numerical results. In this figure, the circled parts of the contact lines have reached the shear strength. This situation affects more than a half of the contact line causing the failure of the wall.

Finally, the masonry compressive failure is predicted for some theoretical walls, e.g. wall MS21S, shown in Figure 11. The vertical stress distribution on the masonry area is plotted. This shows that the compressive strength of the masonry has been reached at mid height of the wall. It has to be remarked that this failure mode was not experimentally observed.

\section{DISCUSSION}

Firstly, it is important to remark that the load-bearing capacity predicted by the model correctly adjusts the experimental results. The average error is within the typical experimental scattering of destructive tests on masonry walls, around 30\%, and it is better than the error obtained with a similar model for non-strengthened walls (see [1]). This fact agrees with the greater uniformity of the structural response showed by the TRM-strengthened walls in comparison with the behaviour of unreinforced masonry walls.

The influence of the Young's modulus and the compressive strength on the capacity of the walls depends on the walls' failure mode. As can be seen in Figure 6, the influence of both parameters is very significant in those cases with small load eccentricities, which failed by shear/compression. In contrast, the response of the walls that fail due to bending/buckling phenomena, which are the ones with the larger load eccentricities and/or slenderness, is less influenced by the Young's modulus and the masonry compressive strength. In these cases, such parameters become less critical for the prediction of the ultimate response. However, an increase of these parameters leads always to some increase of the resulting load-bearing capacity.

The load-bearing capacity of the walls subjected to larger load eccentricity tends to be underestimated by the proposed numerical model. A conservative definition of the mechanical variables which directly describe the bending response of the walls -mostly the flexural strength of the masonry, $f_{x t}$ or the TRM defining variables might explain this underestimation tendency.

In addition and according with the results from Figure 6, the load-bearing capacity calculated by the numerical model decreases with the increase of the eccentricity of the applied load. This result meets the typical response of the eccentrically loaded walls (see [1]), so the numerical model correctly reproduces the theoretical results. However, the experimental results do not follow this common tendency because these are influenced by the use of 
different TRM systems. Thus, additional experimental evidences seem necessary to clarify this experimental unexpected result.

The greater lateral stiffness of the experimental response of the tested walls in comparison with the numerically obtained curves (Figure 7) might be due to the possible underestimation of the value of the Young's modulus of the masonry. This hypothesis would also explain the tendency of the model to underestimate the load-bearing capacity of the walls. In addition, the difference between the shape of the numerical and experimental curves in Figure 7 suggest that the implemented constitutive model for the masonry in compression might be too simple to fully predict the response of the wall. However, a more accurate description of this material (e.g. parabolic) might be not necessary if the only aim of the model is to predict the load-bearing capacity of TRM-strengthened walls. Thus, it would be interesting to improve the experimental procedures in order to obtain a more realistic measurement of the Young's modulus of the masonry to be used in the model. The next step might be implementing more complex constitutive equations for representing the masonry response.

Regarding the comparison of the numerical results with the ones obtained using the referenced analytical method (Table 6), it has to be noticed that this analytical approach uses experimental data (the load-bearing capacity) as an input parameter to predict the corresponding maximum bending moment which is compared with the experimental one. In contrast, the numerical model only uses the material properties and the geometric definition as input data. Moreover, the analytical approach always considers the masonry compressive failure for the analysed cases, whereas the numerical model is able to predict the structural response considering different failure modes and can predict the load-bearing capacity for a wider range of boundary conditions and loading patterns than the analytical tool. The better accuracy of the analytical approach for the analysed cases can be justified by these facts.

The significant scattering of the numerical results (even greater than the experimental ones according with the data in Table 6) is pointing out that the implemented model is extremely sensitive to the value of the load eccentricity and to the variables which define the tensile response of the TRM. In addition, it is worth noticing that the numerical model only overestimates the experimental cases of the walls strengthened with carbon fibre grids. This result might point out that the adherence between the inorganic matrixes and the carbon fibre grids is not reliable. This idea is supported by previous evidences (see [33]).

The results in Figure 8 show that the implemented fictitious inclined contact is an effective and simple way to model the compressive/shear failure of the masonry near the ends of the TRMstrengthened brick masonry walls. When this type of contact is appropriately defined, the compressive/shear failure is correctly activated in the cases where it is actually observed (see Figure 10 right), while it does not activate in the cases that are expected to fail due to mechanism formation (Figure 8).

Additionally, the numerical results of Figure 8 show that TRM strengthening limits and even prevents the development of the mechanism failure mode. The strengthening system reduces significantly the lateral deformation of the walls and therefore limits the second order bending effects, leading to an increase of the load-bearing capacity. In contrast, TRM strengthening does not affect the vertical wall deformability because this behaviour is mostly controlled by 
the properties of the masonry. This theoretical reasoning is completely supported by the results of the implemented numerical tool.

Moreover, it might be expected to observe an increase of the vertical stiffness of the walls when both sides of the wall are strengthened, because in this case both masonry and TRM influence the compressive response of the structure. This hypothesis is supported by the numerical results plotted in Figure 8 and Figure 9, which show the stiffer vertical response of the walls HS21S and MS21S.

As should be expected, the more slender walls ( $\mathrm{H}$ series) show greater lateral deformations than less slender cases ( $M$ series). This is clearly observed in Figure 8 and Figure 9 , showing the ability of the implemented model at considering the effect of the main variables defining the studied problem.

In addition, the little difference between placing one, two or four fibre grids in a TRMstrengthening layer, which has been showed by the results from Table 7 and Figure 9, might be related with the fact that all these theoretical cases failed by a compressive/shear collapse of the masonry near the wall's ends. Taking into account that this failure mode is controlled by the masonry, the effect of modifying the characteristics of the TRM is limited and only slightly affects the lateral deformation of these structures. Thus, the numerical results help to understand that there is a remarkable difference between unreinforced masonry walls, which failed by mechanism formation, and TRM-strengthened masonry walls with the fibre grid applied on the side subjected to tensile efforts, which mostly failed by compressive/shear failure of the masonry. However, the influence of placing extra fibre grids on the strengthened side is not significant because the failure mode is controlled by the masonry.

The simulations point out that strengthening both sides of the walls increases their lateral stiffness. This response is related with the increase of the thickness of the wall's section and the reduction of the eccentricity of the load with respect to the original section. Finally, the failure mode changes when strengthening both sides, which may turn from compressive/shear failure of the masonry near the endings of the wall to the masonry compressive collapse at mid-height, according with the numerical results and the curves in Figure 9. This change in the failure mode may explain the fact that the lateral deformation associated with the maximum load for the wall of the M series (MS21S) is greater than the corresponding deformation of the comparable wall of the H series (HS21S) although this second case is characterised by a greater slenderness.

From Table 7, it can noticed that the most slender walls ( $\mathrm{H}$ series), which are expected to be more critically affected by second order effects, are the ones whose performance is increased more significantly when applying a TRM-strengthening layer at the tensile side, indicating that the proposed strengthening option is especially effective to avoid the bending-buckling failure. In turn, strengthening both sides of the wall might be considered as the optimum intervention against bending-buckling failure as it limits the lateral deformation and increases the loadbearing capacity. In addition to such advantage, applying TRM on both sides may be necessary in practice due to the difficulty of foreseeing the value and sign of the load eccentricity or real walls, which may even vary depending on the load conditions. 
In Figure 10 left, it is observed that the discretisation of the TRM influences the position of the joints that open when the mechanism formation failure mode is developed. Regarding the compressive/shear failure of the masonry near the endings of the wall, it has been observed that this failure mode happens, in the numerical simulations, when the shear strength is reached in more than a half of the considered dividing line. This result (Figure 10 right) is related by the shear resistance decrease defined by the CZM model. Thus, when a little more than a half of the contact area has reached its maximum strength, there is not resisting nodes available to bear the applied load and the modelled wall collapses. The last failure mode (Figure 11), which corresponds to the masonry compressive collapse at mid-height, is predicted by the model but not observed in the experimental campaign. According to the numerical simulation, this failure mode only occurs in walls with small slenderness and/or high amount of strengthening, and especially in the walls strengthened at both sides. In these cases, the second order bending effects are of limited significance.

\section{CONCLUSIONS}

A numerical model for the analysis of the structural response of TRM-strengthened brickwork walls subjected to eccentric axial load has been presented along with the results of a parametric analysis on the capacity of strengthened walls. The analysis of the obtained results supports the accuracy of the model and its usefulness for understanding the mechanical response of the considered problem. The numerical model provides an efficient calculation tool affording acceptable results, from an engineering point of view, in comparison with the experimental ones. The different assumptions considered in the formulation of the model (as the use of fictitious contacts) have shown to be valid and actually contribute to its efficiency. The relative error and scattering of the numerical results, which are due to the remarkable influence of the geometric and TRM characteristics, are within the range of the experimental scattering of tests on masonry walls (around $30 \%$ ). The proposed model predicts conservative results in most of the cases and especially when the response is mostly determined by the compressive strength. The influence of the type of TRM or the number of fibre grids placed in the TRM is correctly simulated by the model. The proposed numerical model correctly predicts all the failure modes which were experimentally observed. In addition, the eccentricity, the slenderness, the strengthening pattern, the Young's modulus, Poisson's ratio, flexural strength and compressive strength of the masonry are identified the more influent parameters.

The parametric analysis on theoretical walls has allowed the following conclusions: a) the tensile strength of the TRM's mortar is a critical parameter; b)strengthening both sides of the walls is necessary for safety reasons and very recommendable to increase their structural performance (as it contributes to reduce the lateral deformation and improves the loadbearing capacity); c)increasing the thickness of the wall and reducing the load eccentricity by strengthening both sides is an efficient solution; d)depending on the geometry and the strengthening pattern, the model suggests a possible failure pattern which has not been experimentally observed: the compressive crushing of the masonry.

In addition, some of the limitations of the numerical model suggest that it would be interesting to improve the experimental determination of the Young's modulus of the masonry, to develop an accurate analytical tool for calculating the energy of fracture, to include a more 
complex constitutive equation for the masonry, to consider a plane stress hypothesis or to analyse the influence of difference variables, including the angle of the fictitious contacts on masonry as further works to upgrade the presented model.

To sum up, the proposed numerical model is useful at predicting the load-bearing capacity of the wide range of TRM-strengthened brick masonry cases, which have been considered, and provides comprehensive information about the mechanical response of this type of structures. 


\section{REFERENCES}

[1] E. Bernat, L. Gil, P. Roca, C. Sandoval, Experimental and numerical analysis of bending-buckling mixed failure of brickwork walls, Constr. Build. Mater. 43 (2013) 1-13. doi:http://dx.doi.org/10.1016/j.conbuildmat.2013.01.025.

[2] E. Bernat, L. Gil, P. Roca, C. Escrig, Experimental and analytical study of \{TRM\} strengthened brickwork walls under eccentric compressive loading, Constr. Build. Mater. 44 (2013) 35-47. doi:http://dx.doi.org/10.1016/j.conbuildmat.2013.03.006.

[3] N. Augenti, F. Parisi, A. Prota, G. Manfredi, In-Plane Lateral Response of a FullScale Masonry Subassemblage with and without an Inorganic Matrix-Grid Strengthening System, J. Compos. Constr. 15 (2011) 578. doi:10.1061/(ASCE)CC.1943-5614.0000193.

[4] C. Papanicolaou, T. Triantafillou, M. Lekka, Externally bonded grids as strengthening and seismic retrofitting materials of masonry panels, Constr. Build. Mater. 25 (2011) 504-514. doi:10.1016/j.conbuildmat.2010.07.018.

[5] L. Garmendia, J.T. San-José, D. García, P. Larrinaga, Rehabilitation of masonry arches with compatible advanced composite material, Constr. Build. Mater. 25 (2011) 4374-4385. doi:10.1016/j.conbuildmat.2011.03.065.

[6] C.G. Papanicolaou, T.C. Triantafillou, M. Papathanasiou, K. Karlos, Textile reinforced mortar (TRM) versus FRP as strengthening material of URM walls: out-of-plane cyclic loading, Mater. Struct. 41 (2007) 143-157. doi:10.1617/s11527-007-9226-0.

[7] C.G. Papanicolaou, T.C. Triantafillou, K. Karlos, M. Papathanasiou, Textilereinforced mortar (TRM) versus FRP as strengthening material of URM walls: inplane cyclic loading, Mater. Struct. 40 (2006) 1081-1097. doi:10.1617/s11527006-9207-8.

[8] M. Malena, G. de Felice, Debonding of composites on a curved masonry substrate: Experimental results and analytical formulation, Compos. Struct. 112 (2014) 194-206. doi:10.1016/j.compstruct.2014.02.004.

[9] J. Harajli, M.H., ELKhatib, H., Tomas San-Jose, Masonry Walls Strengthened Using Fibre Textile-Mortar System: Experimental Evaluation of Out-of-Plane Cyclic Response, in: CSHM-3, Ottawa-Gatineau, Canada, 2010: pp. 19-32.

[10] D. García, Experimental and numerical analysis of stone masonry walls strengthened with advanced composite materials, PhD. Thesis, Escuela de Ingenieria de Bilbao, 2009. 
[11] P. Larrinaga, C. Chastre, H.C. Biscaia, J.T. San-José, Experimental and numerical modeling of basalt textile reinforced mortar behavior under uniaxial tensile stress, Mater. Des. 55 (2014) 66-74. doi:10.1016/j.matdes.2013.09.050.

[12] N. Williams Portal, K. Lundgren, A.M. Walter, J.O. Frederiksen, L.N. Thrane, Numerical modelling of textile reinforced concrete, in: Proc. 8th Int. Conf. Fract. Mech. Concr. Concr. Struct. Fram. 2013, 2013: pp. 886-897.

[13] F.G. Carozzi, G. Milani, C. Poggi, Mechanical properties and numerical modeling of Fabric Reinforced Cementitious Matrix (FRCM) systems for strengthening of masonry structures, Compos. Struct. 107 (2014) 711-725. doi:10.1016/j.compstruct.2013.08.026.

[14] H.M. Elsanadedy, T.H. Almusallam, S.H. Alsayed, Y. a. Al-Salloum, Flexural strengthening of RC beams using textile reinforced mortar - Experimental and numerical study, Compos. Struct. 97 (2013) 40-55. doi:10.1016/j.compstruct.2012.09.053.

[15] A. Si Larbi, A. Agbossou, P. Hamelin, Experimental and numerical investigations about textile-reinforced concrete and hybrid solutions for repairing and/or strengthening reinforced concrete beams, Compos. Struct. 99 (2013) 152-162. doi:10.1016/j.compstruct.2012.12.005.

[16] Y.A. Al-Salloum, H.M. Elsanadedy, S.H. Alsayed, R.A. Iqbal, Experimental and Numerical Study for the Shear Strengthening of Reinforced Concrete Beams Using Textile-Reinforced Mortar, J. Compos. Constr. 16 (2012) 74-90. doi:10.1061/(ASCE)CC.1943-5614.0000239.

[17] F. Schladitz, M. Frenzel, D. Ehlig, M. Curbach, Bending load capacity of reinforced concrete slabs strengthened with textile reinforced concrete, Eng. Struct. 40 (2012) 317-326. doi:10.1016/j.engstruct.2012.02.029.

[18] M.S. Alhaddad, N.A. Siddiqui, A.A. Abadel, S.H. Alsayed, Y.A. Al-Salloum, Numerical Investigations on the Seismic Behavior of FRP and TRM Upgraded RC Exterior Beam-Column Joints, J. Compos. Constr. 16 (2012) 308-321. doi:10.1061/(ASCE)CC.1943-5614.0000265.

[19] A. Cecchi, G. Milani, A. Tralli, In-plane loaded CFRP reinforced masonry walls: mechanical characteristics by homogenisation procedures, Compos. Sci. Technol. 64 (2004) 2097-2112. doi:10.1016/j.compscitech.2004.03.009.

[20] G. Milani, Homogenized limit analysis of FRP-reinforced masonry walls out-ofplane loaded, Comput. Mech. 43 (2008) 617-639. doi:10.1007/s00466-0080334-7.

[21] Y. Zheng, S. Taylor, D. Robinson, Nonlinear finite element analysis of masonry arch bridges reinforced with FRP, in: 6th Int. Conf. Arch Bridg., Fuzhou, China, 2010: pp. 838-845. 
[22] S.S. Mahini, a. Eslami, H.R. Ronagh, Lateral performance and load carrying capacity of an unreinforced, CFRP-retrofitted historical masonry vault - A case study, Constr. Build. Mater. 28 (2012) 146-156.

doi:10.1016/j.conbuildmat.2011.08.013.

[23] G. Milani, Kinematic FE limit analysis homogenization model for masonry walls reinforced with continuous FRP grids, Int. J. Solids Struct. 48 (2011) 326-345. doi:10.1016/j.ijsolstr.2010.10.007.

[24] S. Sanchezbeitia, Stresses analysis at the Altes Museum of Berlin by means of the Hole-Drilling technique (Donostia Method), Constr. Build. Mater. 21 (2007) 1680-1687. doi:10.1016/j.conbuildmat.2006.05.052.

[25] G. Milani, P.B. Lourenço, A. Tralli, Homogenised limit analysis of masonry walls, Part I: Failure surfaces, Comput. Struct. 84 (2006) 166-180.

doi:10.1016/j.compstruc.2005.09.005.

[26] G. Milani, M. Pizzolato, A. Tralli, Simple numerical model with second order effects for out-of-plane loaded masonry walls, Eng. Struct. 48 (2013) 98-120. doi:10.1016/j.engstruct.2012.08.029.

[27] E. Bertolesi, F.G. Carozzi, G. Milani, C. Poggi, Numerical modeling of Fabric Reinforce Cementitious Matrix composites (FRCM) in tension, Constr. Build. Mater. 70 (2014) 531-548. doi:10.1016/j.conbuildmat.2014.08.006.

[28] ACl Committee 549, Design and construction of externally bonded FRCM systems (ACI 549.4R-13), (2013).

[29] V. Bosiljkov, I.Z. Totoev, J.M. Nichols, Shear modulus and stiffness of brickwork masonry : An experimental perspective, (2003) 1-22.

[30] G. Alfano, M.A. Crisfield, Finite Element Interface Models for the Delamination Anaylsis of Laminated Composites: Mechanical and Computational Issues, Int. J. Numer. Methods Eng. 50 (2001) 1701-1736.

[31] European Committee for Standardization, Eurocode 6: Design of masonry structures. Part 1-1: General rules for buildings. Rules for reinforced and unreinforced masonry., Versión en, AENOR, Madrid, 1997.

[32] R. Pluijm, Material properties of masonry and its components under tension and shear, in: V.V. Neis (Ed.), 6th Can. Mason. Symp., Saskatoon, Saskatchewan, Canada, 1992: pp. 675-686.

[33] E. Bernat-Maso, C. Escrig, C. a. Aranha, L. Gil, Experimental assessment of Textile Reinforced Sprayed Mortar strengthening system for brickwork wallettes, Constr. Build. Mater. 50 (2014) 226-236. doi:10.1016/j.conbuildmat.2013.09.031. 


\section{List of tables}

Table 1 Geometric characteristics and strengthening system of the experimentally tested walls Table 2. Experimental and theoretical properties of the bricks and mortars used in the research. Coefficient of variation of the experimentally determined values in brackets. The experimental information is detailed in [2].

Table 3. Properties of the fibre grids used in the studied TRM solutions. Manufacturer provided values. Table included in [2].

Table 4 Geometric characteristics and strengthening system of the theoretical walls Table 5. Properties of the contacts used in the FEA

Table 6. Analytical and numerical results for the tested TRM strengthened walls Table 7. Load-bearing capacity of the theoretical walls depending on the slenderness of the wall and the strengthening pattern 


\begin{tabular}{cccccccc} 
Wall & $\begin{array}{c}\text { Effective height } \\
(\mathbf{m m})\end{array}$ & $\begin{array}{c}\boldsymbol{d} \\
(\mathbf{m m})\end{array}$ & $\begin{array}{c}\text { TRM } \\
\text { mortar }\end{array}$ & $\begin{array}{c}\text { TRM fibre } \\
\text { grid }\end{array}$ & $\begin{array}{c}\text { Connectors } \\
\text { \# fibre } \\
\text { grids }\end{array}$ & $\begin{array}{c}\boldsymbol{t}_{\text {TRM }} \\
(\mathbf{m m})\end{array}$ \\
\hline W\#21 & 1832 & 0.0 & $\mathrm{M}$ & $\mathrm{G}$ & 0 & 1 & 13.0 \\
\hline$W \# 22$ & 1827 & 0.0 & $\mathrm{M}$ & $\mathrm{G}$ & 0 & 1 & 8.0 \\
\hline$W \# 23$ & 1822 & 5.5 & $\mathrm{R}$ & $\mathrm{G}$ & 0 & 1 & 9.5 \\
\hline$W \# 24$ & 1840 & 0.5 & $\mathrm{R}$ & $\mathrm{G}$ & 0 & 1 & 9.0 \\
\hline$W \# 25$ & 1828 & 0.5 & $\mathrm{R}$ & $\mathrm{G}$ & 0 & 2 & 7.5 \\
\hline$W \# 26$ & 1823 & 6.0 & $\mathrm{M}$ & $\mathrm{G}$ & 0 & 2 & 8.0 \\
\hline$W \# 27$ & 1822 & 9.0 & $\mathrm{X}$ & $\mathrm{C}$ & 0 & 1 & 8.0 \\
\hline$W \# 28$ & 1828 & 0.5 & $\mathrm{X}$ & $\mathrm{C}$ & 6 & 1 & 9.0 \\
\hline$W \# 29$ & 1827 & 8.5 & $\mathrm{X}$ & $\mathrm{C}$ & 9 & 1 & 11.0 \\
\hline
\end{tabular}

Table 1 Geometric characteristics and strengthening system of the experimentally tested walls

\begin{tabular}{ccccc} 
Material & $\begin{array}{c}\text { Flexural } \\
\text { strength, } f_{x} \\
(\mathbf{M P a})\end{array}$ & $\begin{array}{c}\text { Compressive strength, } \boldsymbol{f}_{c m} \\
(\mathbf{M P a})\end{array}$ & $\begin{array}{c}\text { Bondin } \\
\mathbf{g} \\
\text { strength, } \\
f_{b}(\mathbf{M P a})\end{array}$ & $\begin{array}{c}\text { Modulus of } \\
\text { elasticity, } \boldsymbol{E} \\
(\mathbf{M P a})\end{array}$ \\
\hline $\begin{array}{c}\text { Bricks } \\
\begin{array}{c}\text { Durland } \\
\text { M7,5 mortar }\end{array}\end{array}$ & $2.8(0.28)$ & $27.9(0.19)$ & -- & $10000^{*}$ \\
\hline $\begin{array}{c}\text { Portland- } \\
\text { based mortar }\end{array}$ & $8.1(0.18)$ & $3.7(0.63)$ & $\begin{array}{c}0.36 \\
(0.18)\end{array}$ & $3000^{*}$ \\
\hline $\begin{array}{c}\text { Lime-based } \\
\text { mortar }\end{array}$ & $6.6(0.03)$ & $42.2(0.27)$ & $2^{*}$ & $11000^{*}$ \\
\hline $\begin{array}{c}\text { Pozzolana- } \\
\text { based mortar }\end{array}$ & $9.4(0.10)$ & $14.5(0.08)$ & $0.8^{*}$ & $8000^{*}$ \\
\hline
\end{tabular}

* Data provided by the producer of the material

Table 2. Experimental and theoretical properties of the bricks and mortars used in the research. Coefficient of variation of the experimentally determined values in brackets. The experimental information is detailed in [1] and [2].

\begin{tabular}{cccc}
$\begin{array}{c}\text { Fibre } \\
\text { grid }\end{array}$ & $\begin{array}{c}\text { Ultimate elongation of the fibre } \\
\text { (\%) }\left(\varepsilon_{\text {ult }}^{\text {fibre }}\right)\end{array}$ & $\begin{array}{c}\text { Tensile strength of the } \\
\text { TRM }(\mathbf{k N} / \mathbf{m})\left(T_{\text {ult }}^{T R M}\right)\end{array}$ & Grid dimensions \\
\hline Glass & 3 & 45 & $25 \mathrm{~mm} \times 25 \mathrm{~mm}$ \\
\hline Carbon & 2.1 & 160 & $10 \mathrm{~mm} \times 10 \mathrm{~mm}$ \\
\hline
\end{tabular}

Table 3. Properties of the fibre grids used in the studied TRM solutions. Manufacturer provided values. Table included in [2]. 


\begin{tabular}{ccccc} 
Wall & Effective Height $(\mathbf{m m})$ & \# strengthened faces & \# fibre grids & $\boldsymbol{t}_{\text {TRM }}(\mathbf{m m})$ \\
\hline H0 & 2900 & --- & --- & -- \\
\hline H0S & 2900 & --- & --- & --- \\
\hline HS11 & 2900 & 1 & 1 & 10.0 \\
\hline HS11S & 2900 & 1 & 1 & 10.0 \\
\hline HS12S & 2900 & 1 & 2 & 10.0 \\
\hline HS14S & 2900 & 1 & 4 & 20.0 \\
\hline HS21S & 2900 & 2 & 1 & 10.0 \\
\hline M0 & 1800 & --- & --- & --- \\
\hline M0S & 1800 & --- & -- & --- \\
\hline MS11 & 1800 & 1 & 1 & 10.0 \\
\hline MS11S & 1800 & 1 & 1 & 10.0 \\
\hline MS12S & 1800 & 1 & 2 & 10.0 \\
\hline MS14S & 1800 & 1 & 4 & 20.0 \\
\hline MS21S & 1800 & 2 & 1 & 10.0 \\
\hline
\end{tabular}

Table 4. Geometric characteristics and strengthening system of the theoretical walls

\begin{tabular}{|c|c|c|c|c|c|c|}
\hline Contact & Walls & $\begin{array}{l}\text { Contact } \\
\text { Failure }\end{array}$ & $\begin{array}{c}f_{x t} \\
(M P a)\end{array}$ & $\begin{array}{c}G_{f}^{\prime} \\
(N / m)\end{array}$ & $\begin{array}{c}\tau_{\max } \\
(\mathrm{MPa})\end{array}$ & $\begin{array}{c}G_{f}^{\prime \prime} \\
(\mathrm{N} / \mathrm{m})\end{array}$ \\
\hline $\begin{array}{l}\text { Real. Masonry } \\
\text { joints }\end{array}$ & All & Debonding & 0.36 & 13 & --- & --- \\
\hline $\begin{array}{l}\text { Real. Masonry- } \\
\text { TRM } \\
\end{array}$ & All & None & --- & --- & --- & --- \\
\hline $\begin{array}{l}\text { Real. Masonry- } \\
\text { support }\end{array}$ & All & None & --- & --- & --- & --- \\
\hline $\begin{array}{l}\text { Fictitious. } \\
\text { Masonry- } \\
\text { Masonry } \\
\text { (inclined) }\end{array}$ & $\begin{array}{l}\text { All except H0, M0, } \\
\text { HS11 and MS11 }\end{array}$ & $\begin{array}{l}\text { Debonding } \\
\text { and Sliding }\end{array}$ & $2.8^{*}$ & 100 & 0.56 & 20 \\
\hline \multirow{8}{*}{$\begin{array}{c}\text { Fictitious. TRM- } \\
\text { TRM }\end{array}$} & $\begin{array}{l}\text { W\#21 W\#22 HS11 } \\
\text { HS11S HS21S MS11 } \\
\text { MS11S MS21S }\end{array}$ & Debonding & 8.1 & 295 & \multirow{8}{*}{--- } & \multirow{8}{*}{--- } \\
\hline & W\#23 W\#24 & Debonding & 6.6 & 240 & & \\
\hline & W\#25 & Debonding & 12.0 & 440 & & \\
\hline & W\#26 & Debonding & 11.3 & 412 & & \\
\hline & W\#27 & Debonding & 20.0 & 733 & & \\
\hline & W\#28 & Debonding & 17.8 & 652 & & \\
\hline & W\#29 & Debonding & 14.5 & 533 & & \\
\hline & $\begin{array}{l}\text { HS12S HS14S } \\
\text { MS12S MS14S }\end{array}$ & Debonding & 9.0 & 330 & & \\
\hline
\end{tabular}

* This value corresponds to the direct tensile strength, not to the flexural tensile strength.

Table 5. Properties of the contacts used in the FEA 


\begin{tabular}{|c|c|c|c|c|c|c|}
\hline Wall & $M^{\text {exp }} /\left(N_{u} \cdot t / 8\right)$ & $M^{\text {analytic }} /\left(N_{u} \cdot t / 8\right)^{(1)}$ & Error (\%) & $N_{\max }^{\text {exp }}(k N)$ & $N_{\max }^{F E A}(k N)$ & Error (\%) \\
\hline W\#21 & 0.648 & 0.765 & 18.1 & 299.7 & 264.6 & -11.7 \\
\hline $\mathrm{W} \# 22$ & 0.828 & 0.841 & 1.6 & 328.6 & 208.2 & -36.7 \\
\hline W\#23 & 0.618 & 0.725 & 17.3 & 270.9 & 215.4 & -20.5 \\
\hline W\#24 & 0.667 & 0.746 & 11.8 & 285.6 & 247.1 & -13.5 \\
\hline W\#25 & 0.787 & 0.906 & 15.1 & 414.0 & 263.0 & -36.5 \\
\hline $\mathrm{W} \# 26$ & 1.027 & 0.926 & -9.8 & 390.3 & 282.4 & -27.7 \\
\hline W\#27 & 0.708 & 0.826 & 16.7 & 345.7 & 333.1 & -3.6 \\
\hline W\#28 & 0.575 & 0.806 & 40.2 & 313.5 & 381.1 & 21.6 \\
\hline W\#29 & 0.865 & 0.844 & -2.4 & 330.2 & 344.1 & 4.2 \\
\hline \multicolumn{3}{|c|}{ rage valu } & 14.8 & & & 19.5 \\
\hline
\end{tabular}

(1) Corresponding to the maximum experimental axial force and according to the analytical formulation

Table 6. Analytical and numerical results for the tested TRM strengthened walls

\begin{tabular}{|c|c|c|c|}
\hline Wall & $\begin{array}{l}\text { Inclined contact } \\
\text { effect } *(\%) \\
\end{array}$ & $\begin{array}{c}\text { Load-bearing capacity } \\
\text { increase } * *(\%)\end{array}$ & $\begin{array}{c}\text { Influence of strengthening } \\
\text { pattern } * * *(\%)\end{array}$ \\
\hline HOS & 0.0 & & \\
\hline HS11S & 0.1 & 133 & \\
\hline HS12S & & 142 & 4 \\
\hline HS14S & & 200 & 29 \\
\hline HS21S & & 745 & 263 \\
\hline MOS & -0.0 & & \\
\hline MS11S & 0.0 & 92 & \\
\hline MS12S & & 100 & 4 \\
\hline MS14S & & 130 & 20 \\
\hline MS21S & & 439 & 181 \\
\hline
\end{tabular}

* Comparison of cases with the same strengthening configuration with and without inclined contacts. H0S is compared with H0, HS11S is compared with HS11, M0S is compared with M0 and MS11S is compared with MS11.

** Comparison with respect to the non-strengthened case. All analysed cases consider the inclined contact in the masonry. HS11S, HS12S, HS14S and HS21S are compared with H0S and MS11S, MS12S, MS14S and MS21S are compared with M0S.

*** Comparison with respect to the cases strengthened with one fibre grid embedded into one mortar layer applied on one side of the wall. HS12S, HS14S and HS21S are compared with HS11S and MS12S, MS14S and MS21S are compared with MS11S.

Table 7. Load-bearing capacity of the theoretical walls depending on the slenderness of the wall and the strengthening pattern 


\section{List of Figures}

Figure 1. Typical geometric model for experimentally tested TRM-strengthened walls Figure 2. Mesh and contacts distribution

Figure 3. Sketch of the typical tensile stress-strain relation of the TRM

Figure 4. Generic compression (left) and tension (right) stress-strain response for the masonry (up) and TRM (down) used in the model.

Figure 5. Normal and tangential force components on the failure plane

Figure 6. Comparison of the numerical and experimental results for the TRMW walls

Figure 7. Experimental and numerical dimensionless force vs. lateral displacement at mid height curves

Figure 8. Influence of the inclined contacts on the structural response of the walls Figure 9. Influence of the strengthening configuration on the structural response Figure 10. Distribution of the normal pressure in the fictitious contacts between TRM parts for wall HS11S (left) and distribution of tangential stresses in the fictitious inclined contacts for wall MS12S

Figure 11. Distribution of the vertical normal stress in the masonry for wall MS21S 


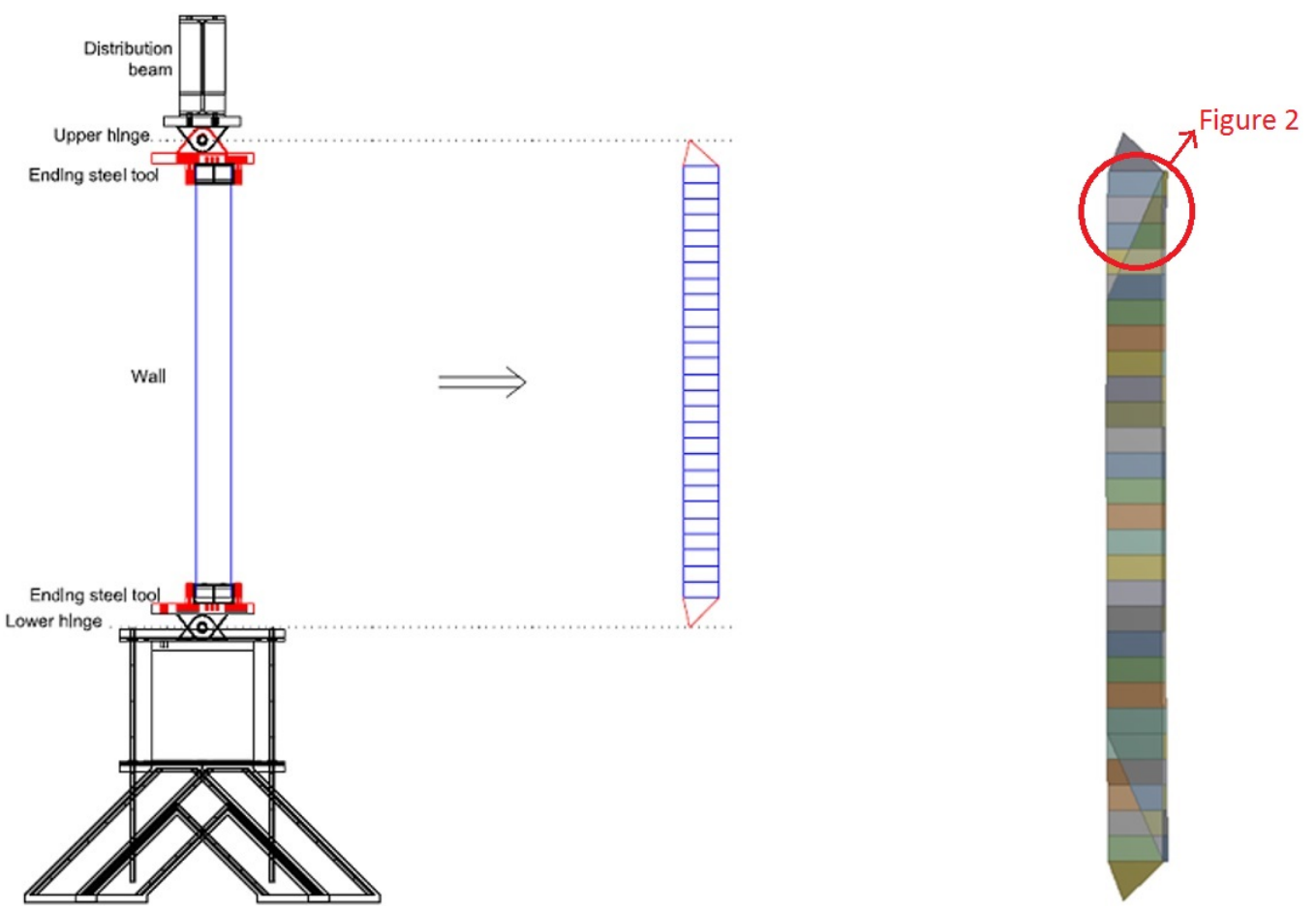

Figure 1. Typical geometric model for experimentally tested TRM-strengthened walls
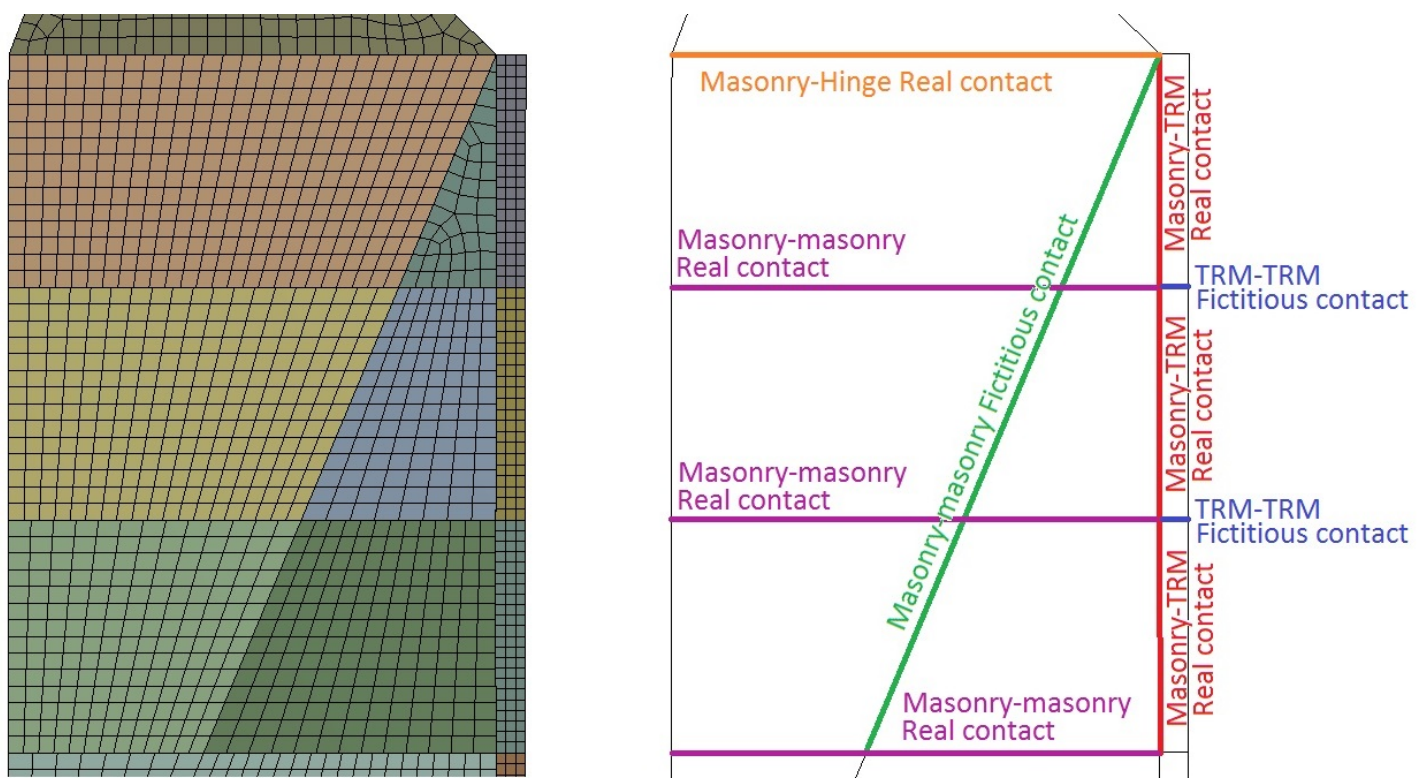

Figure 2. Mesh and contacts distribution 


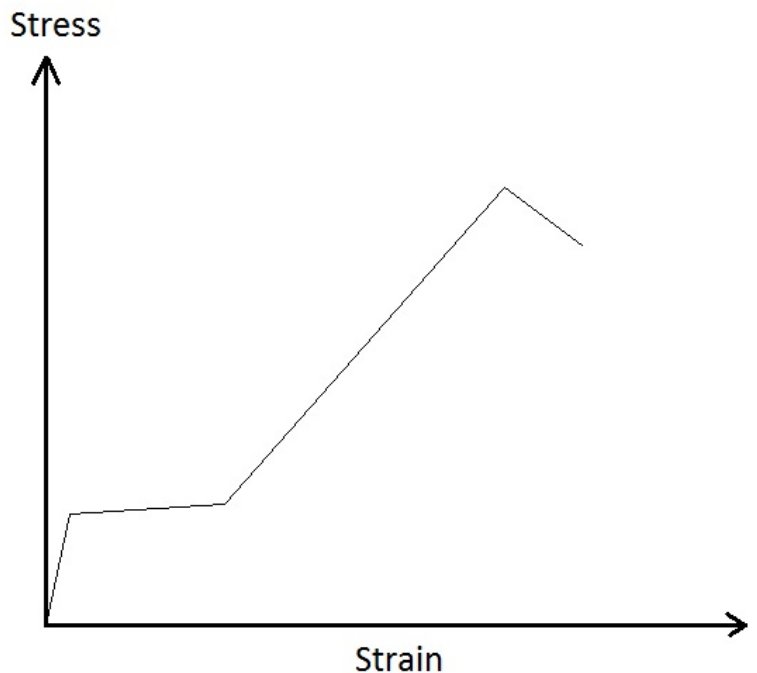

Figure 3. Sketch of the typical tensile stress-strain relation of the TRM
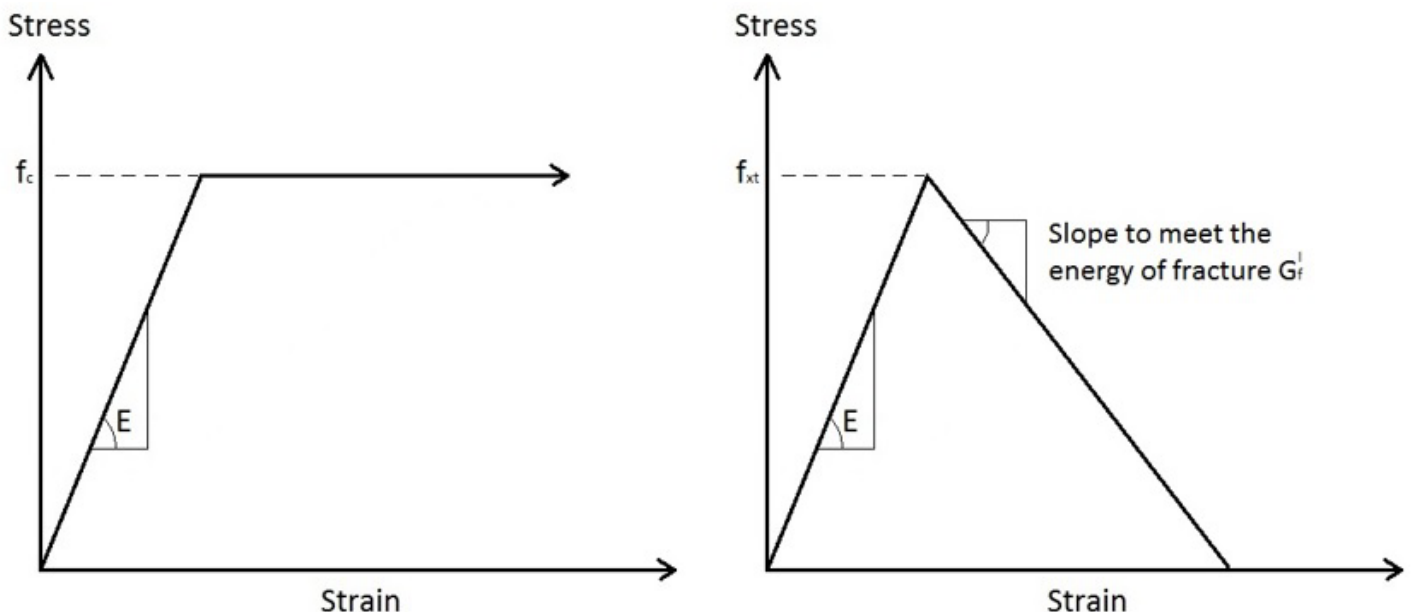

Figure 4. Generic compression (left) and tension (right) stress-strain response for the masonry and TRM used in the model. The compressive $\left(f_{c}\right)$ and tensile $\left(f_{x t}\right)$ strength in the sketch is the one corresponding to each material as it is the Young's modulus $(E)$. 

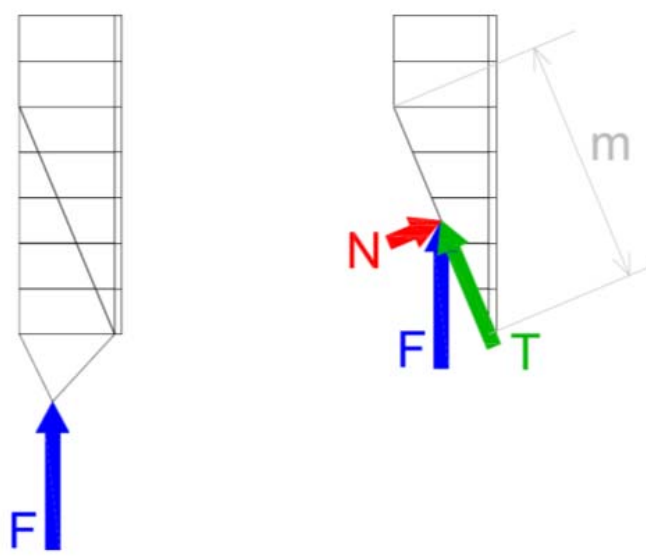

Figure 5. Normal and tangential force components on the failure plane

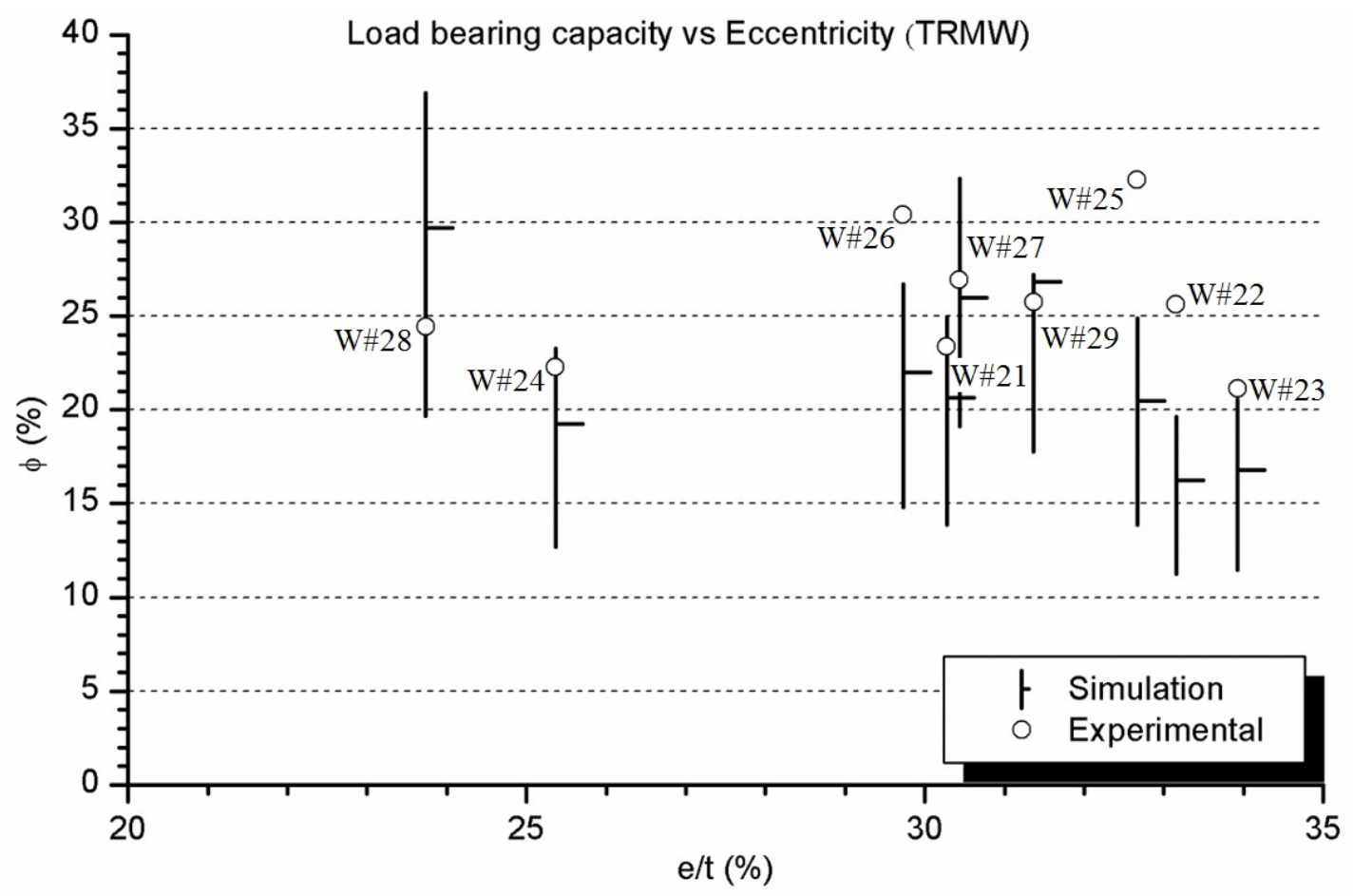

Figure 6. Comparison of the numerical and experimental results for the TRMW walls 

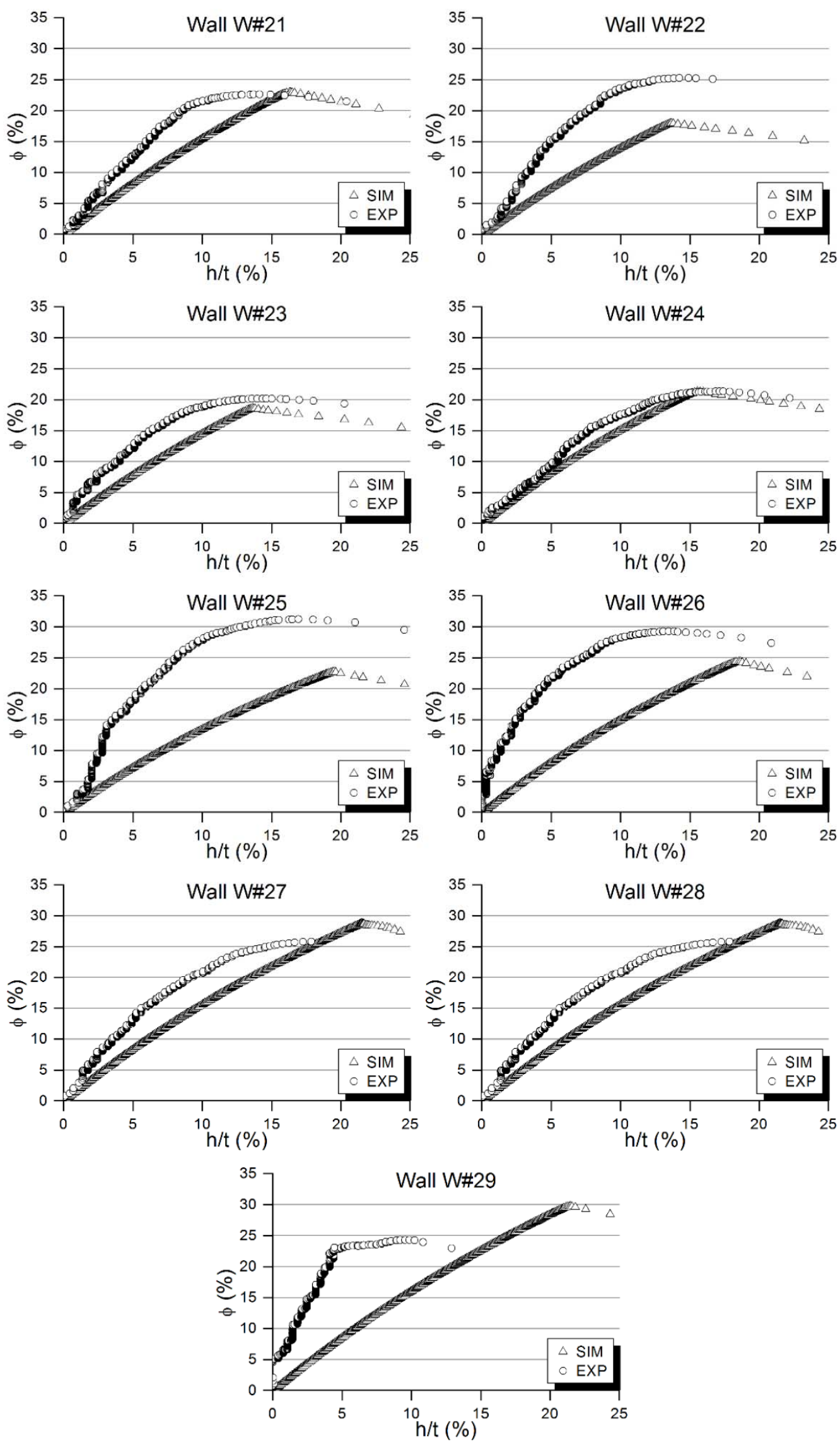

Figure 7. Experimental and numerical dimensionless force vs. lateral displacement at mid height curves 

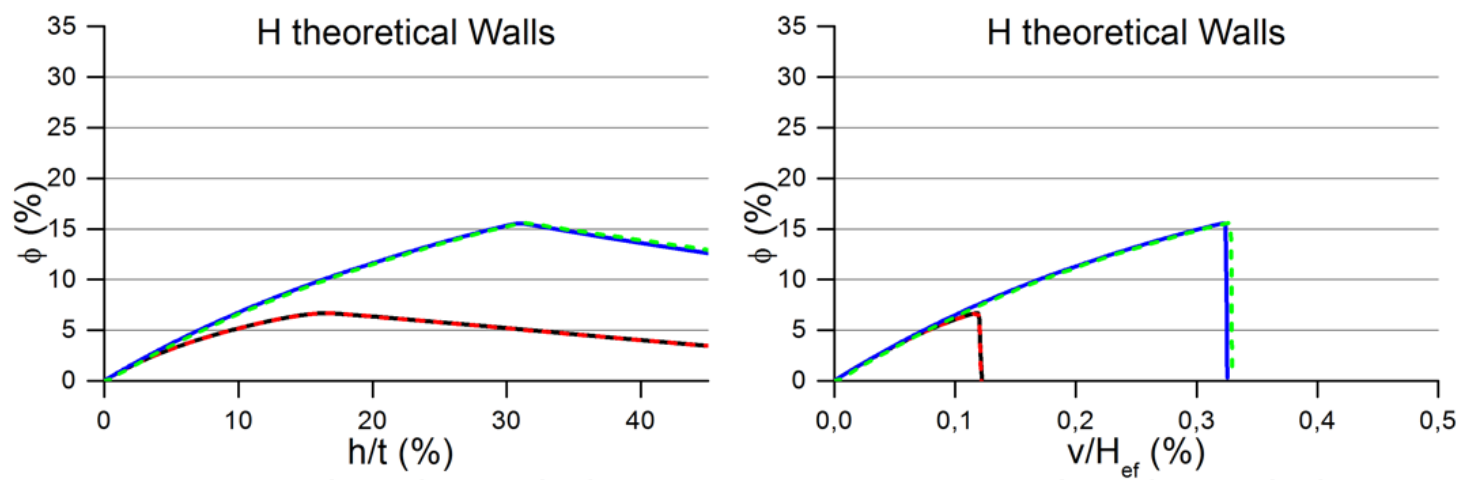

- HO -- HOS - HS11 -- HS11S

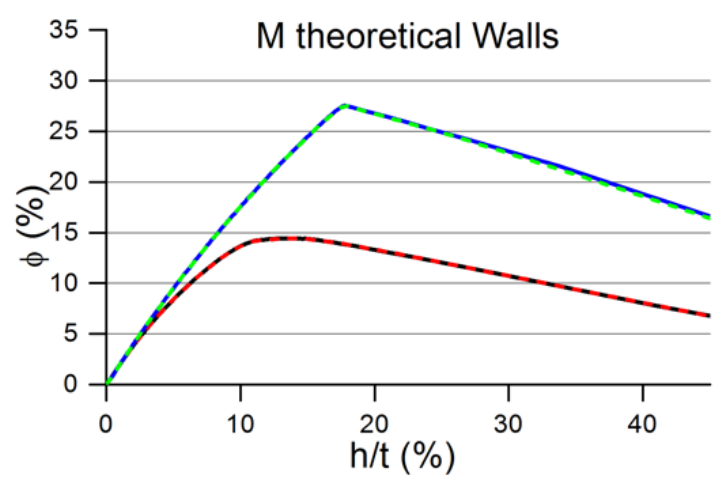

- HO - - HOS - HS11 -- HS11S

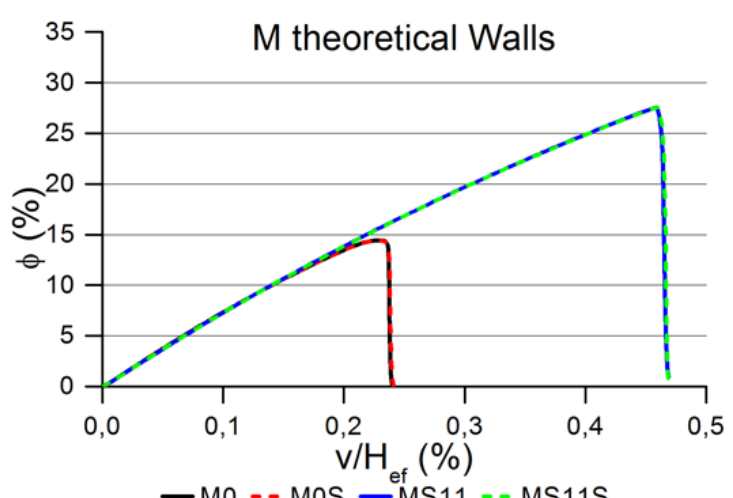

- MO - - MOS - MS11 -- MS11S

Figure 8. Influence of the inclined contacts on the structural response of the walls
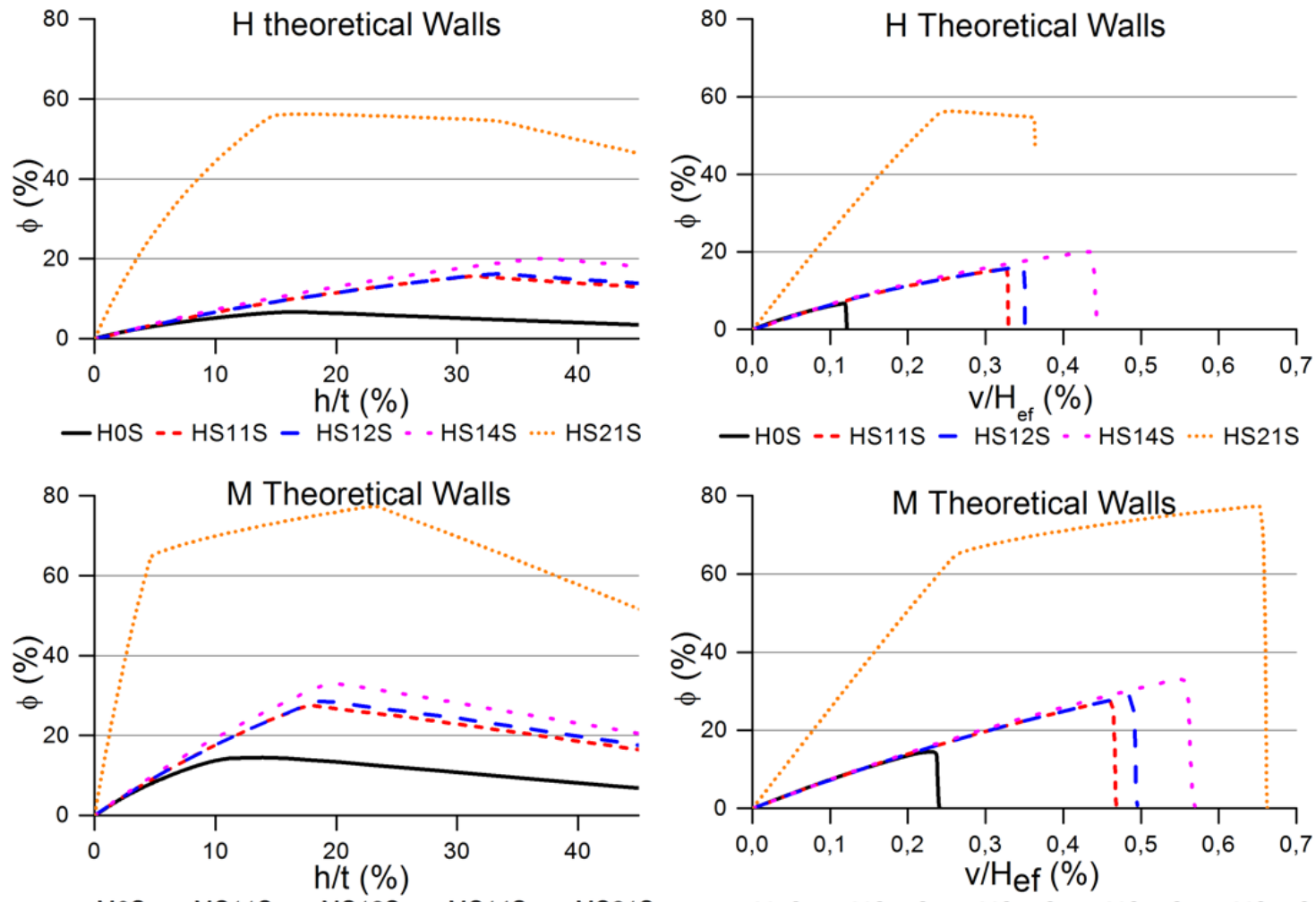

-MOS --MS11S - MS12S -.MS14S …MS21S

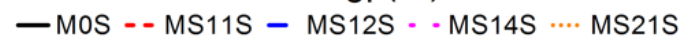

Figure 9. Influence of the strengthening configuration on the structural response 

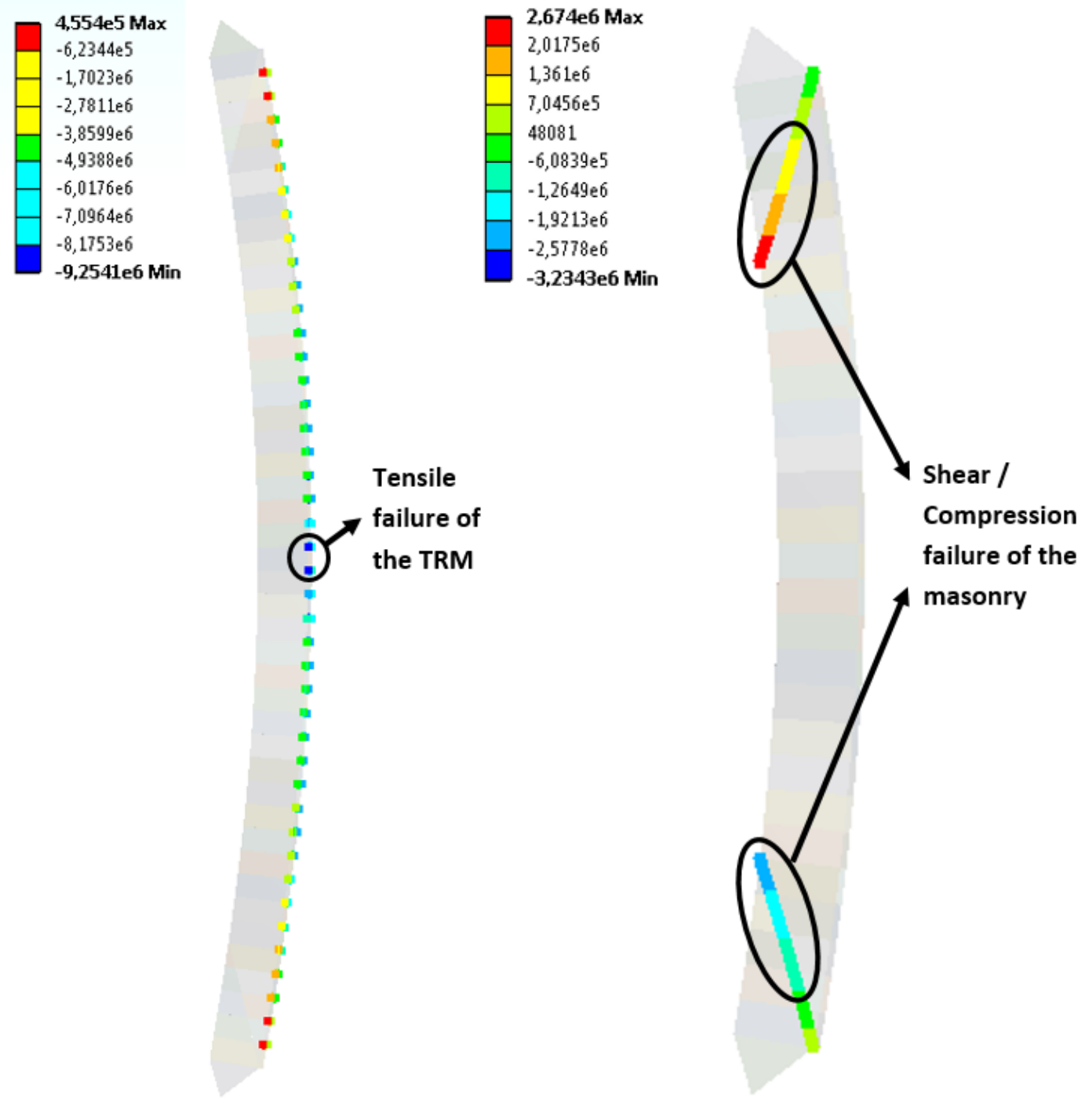

Figure 10. Distribution of the normal pressure in the fictitious contacts between TRM parts for wall HS11S (left) and distribution of tangential stresses in the fictitious inclined contacts for wall MS12S 


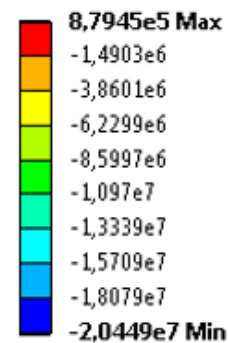

Compressive failure of the masonry

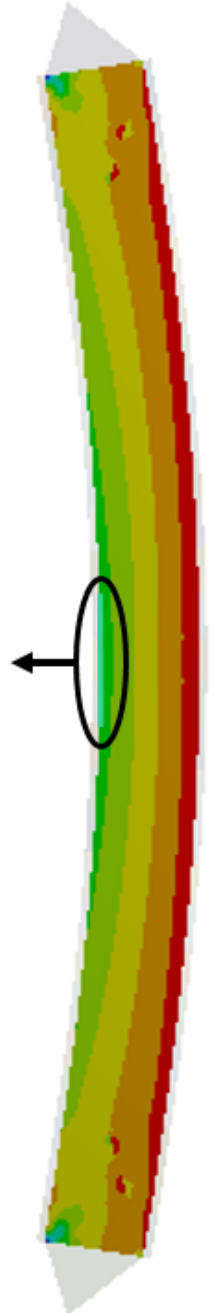

Figure 11. Distribution of the vertical normal stress in the masonry for wall MS21S 